\title{
Energy Response Analysis of Continuous Beam Bridges with Friction Pendulum Bearing by Multihazard Source Excitations
}

\author{
Bing Li, ${ }^{1}$ Bin Wang $\mathbb{D}^{2},{ }^{2}$ Shaohua Wang, ${ }^{3}$ and Xiao $\mathrm{Wu}^{3}$ \\ ${ }^{1}$ School of Mechanical Engineering, North China University of Water Resources and Electric Power, Zhengzhou 450045, China \\ ${ }^{2}$ College of Engineering, Design and Physical Sciences, Brunel University London, London, UK \\ ${ }^{3}$ School of Mechanical Engineering, Southwest Jiaotong University, Chengdu 610031, China
}

Correspondence should be addressed to Bin Wang; bin.wang@brunel.ac.uk

Received 11 October 2019; Revised 2 January 2020; Accepted 21 February 2020; Published 6 July 2020

Guest Editor: Vasant Matsagar

Copyright (c) 2020 Bing Li et al. This is an open access article distributed under the Creative Commons Attribution License, which permits unrestricted use, distribution, and reproduction in any medium, provided the original work is properly cited.

\begin{abstract}
Based on the principle of conservation of energy, analytical modelling of the energy response of continuous beam bridges with friction pendulum bearing (FPB) was carried out for foundation-induced vibrations. A three-dimensional finite element analysis of a multispan continuous concrete girder bridge with FPB was established using the nonlinear time-history method to verify the accuracy of analytical modelling. The influence of the friction coefficient and isolation period of the FPB on the energy response of isolated bridge was then investigated under multihazard source excitations (e.g., El Centro and Taft waves) with different dominant periods and durations. The variations of structural response energy, sliding displacement, energy dissipation ratio, and acceleration of the isolated bridges are plotted. The results of analytical modelling and finite element simulation show good agreement. In addition, there exist particular values of the friction coefficient and isolation period of FPB, for which the structural response energy of the isolated bridges attains the minimum value. The optimal parameters of FPB are greatly influenced by seismic waves, and the friction coefficient of FPB should be increased with the increase of seismic fortification intensity. In addition, the energy dissipation capacity of FPB used in isolated bridge is excellent.
\end{abstract}

\section{Introduction}

Seismic isolation devices are now widely used for protection and retrofit of bridges. The purpose of the isolation devices is to insulate the dynamic movements of the superand the substructures (e.g., the main beam and the pier of the bridge, see Figure 1), to provide a form of damping force to dissipate kinetic energy, and to reduce the relative displacement of movement between the structure components [1-3]. Due to their potential effectiveness in reducing bridge damages, isolation devices have been studied extensively for their performance. Tubaldi et al. [4] proposed a formulation for the seismic assessment of partially restrained seismically isolated (PRSI) bridges based on the complex modes superposition method. Zhang et al. [5] proposed a new isolation device FRPEIs, and it is feasible to use FRPEIs in seismic isolation of short span bridges in low seismic regions. Ismail et al. [6, 7] carried out numerical simulation of the seismic performance of cable-stayed bridges using a Roll-N-Cage (RNC) isolator and showed that the RNC isolator is a convenient isolation system in protecting cable-stayed bridges against near-fault (NF) earthquakes. Zhong et al. [8] studied the influences of the peak ground accelerations, the principal dynamic parameters on the input energy, and the hysteretic energy ratio using lead rubber bearing as isolation devices. Different isolation designs were studied by Dicleli et al. [9], Taflanidis [10], and Ates and Constantinou [11] for their effectiveness against seismic waves, including the probabilistic performance, and for applications to different bridge designs, such as for curved bridges and cable-stayed bridges. Jangid $[2,12]$ studied the equivalent linearization approximate method of isolated bridges using lead-rubber bearing (LRB), the results showed the yield strength of LRB, and the bidirectional interaction of bearing restoring forces had considerable effects on the seismic response of bridges. 


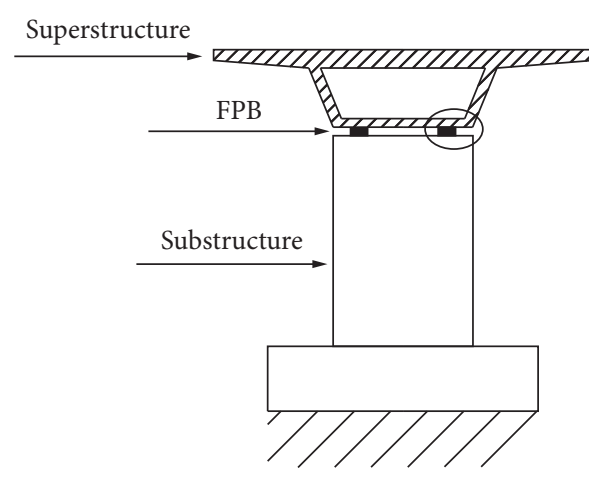

(a)

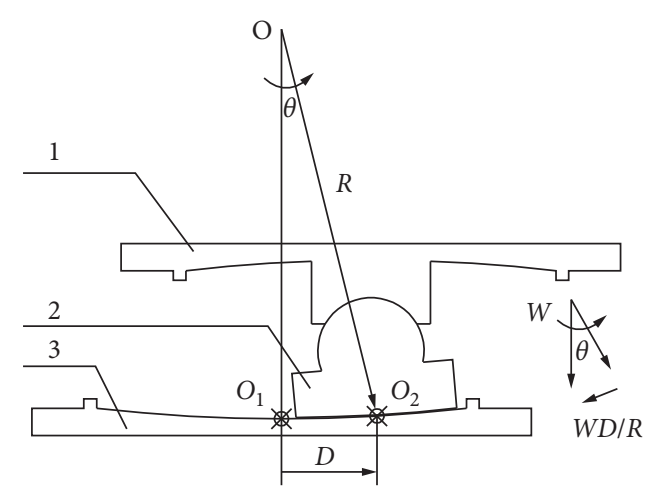

(b)

Figure 1: (a) Isolated bridge with 2 FPBs in view of the axial direction of the bridge. (b) Structural illustration of a FPB (circled in (a)), (1) upper support plate, (2) articulated slider, and (3) lower support plate.

Among various isolation devices, the design of friction pendulum bearing (FPB) has gained strong popularity due to its simplicity in design, effectiveness of energy dissipation, the capacity of self-returning to the original position, and low cost of construction and maintenance. A FPB utilizes a spherical surface for the contact between the super- and substructures. Such surfaces allow sliding movement between the two contacting bodies to dissipate energy through friction. The spherical profile of the contact surfaces also allows the superstructure to return to its balanced position under gravity [13]. Compared with other isolation devices, FPB has better vertical bearing capacity, energy dissipation capacity, durability, among other advantages [14, 15]. Lei et al. [16] studied the dynamic characteristics and responses of two curved bridges considering or not bearings friction sliding isolation used shaking table tests, and concluded that the isolation model curved bridge suffered less seismic damage than the seismic model curved bridge. Dicleli and Mansour [17] showed that the use of FPB can mitigate seismic forces and eliminate the need for retrofitting the substructure components of the bridge.

Several studies have been conducted for seismic response and optimization of FPB system subjected to random earthquake. Hwang et al. [18] studied the isolated regular bridges, and suggested that a bridge can be modelled as a two-degree of freedom system underground excitations. Jangid $[19,20]$ studied the seismic response of a multistorey building and bridge isolated by the friction pendulum system using equivalent linearization system, and they concluded that there are optimum friction coefficient and isolation period of the FPS, for which the acceleration of the top floor or deck attains a minimum value, and the optimum friction coefficient varies with the change of seismic fortification intensity. Ates et al. [21] investigated the effect of the spatially varying earthquake ground motions on the stochastic responses of isolated bridges with FPS, and a calculation method using equivalent linearization techniques for the response amplitude of isolated bridges is proposed. Eröz et al. [22, 23] investigated the effects of modelling and bridge design parameters on the seismic response of FPSisolated bridges through a $3 \mathrm{D}$ analytical model with the nonlinear time-history method. Saha et al. [24, 25] studied the response of the highway bridge isolated with a polynomial friction pendulum isolator (PFPI) and passive hybrid control system, and the result indicated that a passive supplement damper with a PFPI system is significantly reducing the seismic response of the highway bridge.

Seismic energy response can better reflect the cumulative damage of the seismic wave on isolated bridge with FPB. The review of above studies indicates that there had not been sufficiently significant information to investigate the influence of the friction coefficient and isolation period of the $\mathrm{FPB}$ on the energy response of isolated bridges in order to minimize the structural response energy. In this paper, we present an analytical solution for the energy and dynamic responses of continuous beam bridges with FPB under seismic wave loading. The purpose is twofold. An analytical model is a simpler tool for the design purpose, particularly at the conceptual stage. Such a model also allows for the identification of key parameters and their effects on the overall performance of the system. In addition, numerical simulations using a commercial finite element code SAP2000 [26] were carried out and compared with the results of the theoretical model, through which the energy response and parameters optimization of FPB were analyzed under multihazard source excitations with different dominant periods and durations. Results show that the analytical and numerical approaches agree well, and the outcome provides useful guidelines for optimal design of FPB.

\section{Mechanical Model of Isolated Continuous Beam Bridges}

2.1. The Friction Pendulum Bearing (FPB). A FPB is a slidingbased seismic isolator, which is installed between the superstructure and the substructure, as shown circled in Figure 1(a). A structural illustration of FPB is shown in Figure 1(b) where part 1 is fixed under the main bridge beam, or the superstructure, and can rotate about part 2 , the articulated slider. The surfaces of part 1 and part 2 are perfectly fit with the same radius of curvature. This ensures that the superstructure remains horizontal [26] during 
movement. Part 2 and part 3 are in a spherical joint with radius $R$ where part 2 can have frictional sliding on part 3 , which is fixed on the top of the pier or the substructure.

Assuming that the superstructure has a horizontal displacement $D$ measured from its original balanced position $O_{1}$ and the corresponding angle of rotation is $\theta$, for a small displacement assumption, the tangential component of the weight of the superstructure $W$ becomes $W \sin \theta \approx W D / R$. This is the main restoring force to bring the superstructure back to its original position after movement. This is in the same principle of a pendulum, thus the name frictional pendulum bearing (FPB) for this type of joint. Such a joint is also called an isolation device as it dissipates the kinetic energy following seismic loading and limits the motion of the bridge upper deck.

The (tangential) force-(horizontal) displacement behavior of a FPB can be approximately described by a bilinear hysteresis model [22], as shown in Figure 2. The forcedisplacement hysteresis loop can be defined by equation (1) where $\mu$ is the kinetic friction coefficient and $R$ the radius of the concave surface. The equivalent linear stiffness $\left(k_{e}\right)$ is illustrated graphically in Figure 2 and defined by equation (2). The period of vibration $\left(T_{p}\right)$ after the activation of an FPB isolator can be defined by equation (3) [3]. where $D_{0}$ is the maximum value of horizontal displacement of FPB in the cyclic movement.

$$
\begin{gathered}
F=\frac{W D_{0}}{R}+\mu W \operatorname{sgn}(\dot{\theta}), \\
k_{e}=\frac{W}{R}+\frac{\mu W}{D_{0}}, \\
T_{p}=2 \pi \sqrt{\frac{R}{g}},
\end{gathered}
$$

For calculating the energy dissipation by the friction effect, $\varepsilon_{1}$ is defined as the equivalent damping ratio following Dicleli and Mansour [17]. A FPB can be simplified equivalently as a viscous spring damper. Letting the energy dissipation of a FPB and that of an equivalent viscous spring damper be the same in one cycle movement, where $\Delta E$ being the hysteretic energy dissipation of a FPB, the equivalent damping ratio of FPB can be obtained as given in equation (4). Details of the derivation are given in Appendix A:

$$
\varepsilon_{1}=\frac{\Delta E}{2 \pi k_{1} D_{0}^{2}}=\frac{4 \mu W D_{0}}{2 \pi D_{0}\left(\left(W D_{0} / R\right)+\mu W\right)}=\frac{2 \mu}{\pi\left(\left(D_{0} / R\right)+\mu\right)} .
$$

2.2. Dynamic Equations. Two FPBs are normally installed between the superstructure and the substructure as shown in Figure 1(a), with equal distribution of the weight of the superstructure on each FPB. A bridge pier typically has less flexural rigidity in the bridge axial direction than that in the

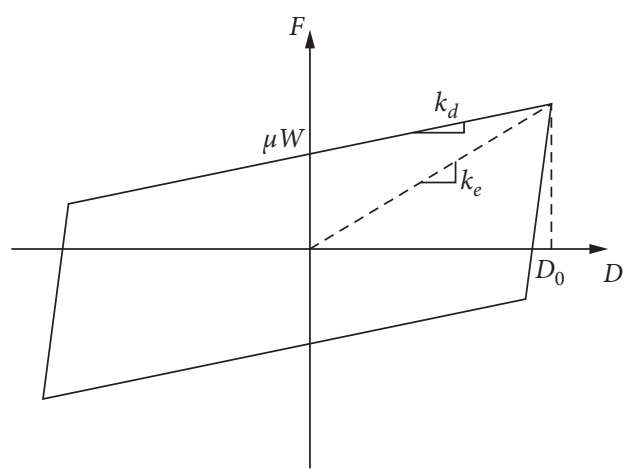

Figure 2: Bilinear hysteresis model.

transverse direction, and the seismic response will occur in the weaker direction. Hence, an isolated bridge can be modeled as a two-degree of freedom system in the axial direction of the bridge [5]. The main beam and pier can be described by an equivalent model shown in Figure 3. $u_{1}$ and $u_{2}$ are the displacements of the main beam and the pier relative to the ground along the bridge direction. $x$ represents the axial direction of the bridge, and $y$ represents the vertical direction of the bridge.

The vibration equation of the system shown in Figure 3 is given by

$$
\begin{aligned}
& {\left[\begin{array}{cc}
m_{1} & 0 \\
0 & m_{2}
\end{array}\right]\left\{\begin{array}{l}
\ddot{u}_{1} \\
\ddot{u}_{2}
\end{array}\right\}+\left[\begin{array}{cc}
c_{1} & -c_{1} \\
-c_{1} & c_{1}+c_{2}
\end{array}\right]\left\{\begin{array}{l}
\dot{u}_{1} \\
\dot{u}_{2}
\end{array}\right\}} \\
& +\left[\begin{array}{cc}
k_{1} & -k_{1} \\
-k_{1} & k_{1}+k_{2}
\end{array}\right]\left\{\begin{array}{l}
u_{1} \\
u_{2}
\end{array}\right\}=-\left[\begin{array}{cc}
m_{1} & 0 \\
0 & m_{2}
\end{array}\right]\left\{\begin{array}{l}
1 \\
1
\end{array}\right\} \ddot{u}_{g},
\end{aligned}
$$

where $m_{1}$ is the equivalent weight of the main bridge beam or the superstructure and $m_{2}$ is the equivalent weight of the pier or the substructure. The top of the pier and the bottom of the main beam are constrained interactively by the isolation devices or FPBs between them. $k_{2}$ is the stiffness of the pier, and $c_{1}$ and $c_{2}$ are the equivalent viscous damping coefficients of the two FPBs and pier, respectively. The energy transferred to the superstructure is mainly consumed by the FPBs; the equivalent viscous damping coefficient of FPB is much larger than that of the main bridge beam, so the equivalent viscous damping coefficient of the main bridge beam is neglected, and the assumption has little effect on the results. $\ddot{u}_{g}$ is the ground acceleration by the seismic wave.

$k_{1}$ is the equivalent linear stiffness of the two FPBs (i.e., $\left.2 k_{e}\right)$. As $D_{0}$ is not a known priori, for calculating $k_{1}$ using equation (2), its value can be chosen as the maximum allowable displacement of the superstructure determined by the design specification, given a conservative design, or through a finite element analysis as a function of the input energy. Detailed discussion on the latter approach using an $\mathrm{FE}$ analysis is beyond the scope of this paper and will be provided elsewhere [27].

Following the classical vibration analysis, we have 


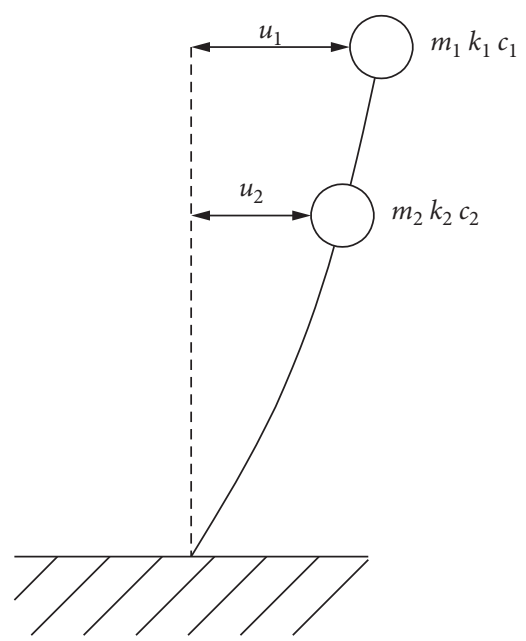

Figure 3: A two-degree-of-freedom system of the continuous beam bridge with 2 FPBs, showing corresponding displacements of the masses.

$$
\begin{aligned}
& \omega_{1}^{2}=\frac{k_{1}}{m_{1}}, \\
& \omega_{2}^{2}=\frac{k_{2}}{\left(m_{2}+m_{1}\right)}, \\
& c_{1}=2 m_{1} \varepsilon_{1} \omega_{1}, \\
& c_{2}=2\left(m_{2}+m_{1}\right) \varepsilon_{2} \omega_{2},
\end{aligned}
$$

where $\omega_{1}$ and $\omega_{2}$ are the fundamental frequencies of the isolated system and $\varepsilon_{1}$ and $\varepsilon_{2}$ the equivalent damping ratios of the FPB and pier, respectively. In practice, $\varepsilon_{2}$ is usually selected as a value recommended by design codes and standards, for instance, 0.05 ; and $\omega_{2}$ and $c_{2}$ are chosen as constants, depending on the design of the pier.

\section{Energy Equations}

For an isolated bridge system, energy equations can be obtained by integrating equation (5) to the relative displacements into a weak form as given in equation (7) (also see [28]). The energy of each mass is first calculated, and the energy of the whole system is then obtained by superposition:

$$
\begin{gathered}
\left.\int_{0}^{t}\left\{\begin{array}{c}
\dot{u}(t) \\
\dot{u}_{2}(t)
\end{array}\right\}^{T}\left[\begin{array}{cc}
m_{1} & 0 \\
0 & m_{2}
\end{array}\right]\left\{\begin{array}{l}
\ddot{u}_{1}(t) \\
\ddot{u}_{2}(t)
\end{array}\right\} \mathrm{d} t+\int_{0}^{t}\left\{\begin{array}{l}
\dot{u}_{1}(t) \\
\dot{u}_{2}(t)
\end{array}\right\}\right\}^{T}\left[\begin{array}{cc}
c_{1} & -c_{1} \\
-c_{1} & c_{1}+c_{2}
\end{array}\right]\left\{\begin{array}{l}
\dot{u}_{1}(t) \\
\dot{u}_{2}(t)
\end{array}\right\} \mathrm{d} t+ \\
\int_{0}^{t}\left\{\begin{array}{l}
\dot{u}_{1}(t) \\
\dot{u}_{2}(t)
\end{array}\right\}^{T}\left[\begin{array}{cc}
k_{1} & -k_{1} \\
-k_{1} & k_{1}+k_{2}
\end{array}\right]\left\{\begin{array}{l}
u_{1}(t) \\
u_{2}(t)
\end{array}\right\} \mathrm{d} t=-\int_{0}^{t}\left\{\begin{array}{l}
\dot{u}_{1}(t) \\
\dot{u}_{2}(t)
\end{array}\right\}^{T}\left[\begin{array}{cc}
m_{1} & 0 \\
0 & m_{2}
\end{array}\right]\left\{\begin{array}{l}
1 \\
1
\end{array}\right\} \ddot{u}_{g}(t) \mathrm{d} t .
\end{gathered}
$$

Terms in the left-hand side of equation (7) represent the kinetic energy $E_{K}(t)$, the mass-damping and friction hysteretic energy $E_{D}(t)$ and $E_{F}(t)$, and the elastic strain energy $E_{P}(t)$. The right-hand side is the seismic input energy $E_{O}(t)$. Equation (7) can be written into equation (8), and the kinetic energy of the system and the elastic strain energy are given in equations (9) and (10):

$$
\begin{gathered}
E_{K}+E_{D}(t)+E_{F}(t)+E_{P}(t)=E_{O}(t), \\
E_{K}(t)=\frac{1}{2} m_{1} \dot{u}_{1}^{2}(t)+\frac{1}{2} m_{2} \dot{u}_{2}^{2}(t), \\
E_{P}(t)=\frac{1}{2} k_{1}\left(u_{1}(t)-u_{2}(t)\right)^{2}+\frac{1}{2} k_{2} u_{2}^{2}(t) .
\end{gathered}
$$

Time step $\Delta t\left(=t_{i+1}-t_{i}\right)$ has an important influence on the computational accuracy and efficiency; so, the appropriate $\Delta t$ is selected by comparing the calculation results of different time steps in the following section. To solve the energies over a small time step $\Delta t$, the following assumptions are made within a time step:

(1) the ground acceleration $\ddot{u}_{g}(t)$ and the point mass velocity $\dot{u}(t)$ vary linearly in time

(2) Acceleration $\ddot{u}(t)$ is assumed constant, taken as the average value over $\Delta t$

While it is also possible to assume a constant value of $\ddot{u}_{g}(t)$ within $\Delta t$, it was found that a linear assumption actually makes calculation simpler. As long as $\Delta t$ is kept small 
enough, there is negligible difference between the linear and constant assumptions.

The energies can then be solved as shown in Figure 4 where the ordinate represents the velocity of the point mass, and the abscissa represents time. Within the time step from $t_{i}$ to $t_{i+1}, \dot{u}(t)$ varies linearly:

$$
\dot{u}(t)=\dot{u}\left(t_{i}\right)+\frac{\ddot{u}\left(t_{i+1}\right)+\ddot{u}\left(t_{i}\right)}{2} t .
$$

Similarly, we can develop the ground acceleration $\ddot{u}_{g}(t)$ as

$$
\ddot{u}_{g}(t)=\ddot{u}_{g}\left(t_{i}\right)+\frac{\ddot{u}_{g}\left(t_{i+1}\right)-\ddot{u}_{g}\left(t_{i}\right)}{\Delta t} t .
$$

Integration of the seismic input energy over the time step can be carried out as

$$
\begin{aligned}
\Delta E_{O}(n) & =\sum_{j=1}^{t_{i+1}} \int_{t_{i}}^{t_{i+1}} m_{j} \dot{u}_{j}(t) \ddot{u}_{g}(t) \mathrm{d} t \\
& =\sum_{j=1}^{\Delta t} \int_{0}^{\Delta t} m_{j} \times\left[\dot{u}_{j}\left(t_{i}\right)+\frac{\ddot{u}_{j}\left(t_{i+1}\right)+\ddot{u}_{j}\left(t_{i}\right)}{2} t\right] \times\left[\dot{u}_{g}\left(t_{i}\right)+\frac{\ddot{u}_{g}\left(t_{i+1}\right)-\ddot{u}_{g}\left(t_{i}\right)}{\Delta t} t\right] \mathrm{d} t \\
& =\sum_{j=1}^{2}\left\{\begin{array}{c}
m_{j} \dot{u}_{j}\left(t_{i}\right) \ddot{u}_{g}\left(t_{i}\right) \Delta t-\frac{m_{j}}{2}\left[\dot{u}_{j}\left(t_{i}\right)\left(\ddot{u}_{g}\left(t_{i+1}\right)-\ddot{u}_{g}\left(t_{i}\right)\right)\right] \Delta t \\
-\frac{m_{j}}{4}\left[\ddot{u}_{g}\left(t_{i}\right)\left(\ddot{u}_{j}\left(t_{i}\right)+\ddot{u}_{j}\left(t_{i+1}\right)\right)\right] \Delta t^{2}-\frac{m_{j}}{6}\left[\left(\ddot{u}_{g}\left(t_{i+1}\right)-\ddot{u}_{g}\left(t_{i}\right)\right)\left(\ddot{u}_{j}\left(t_{i}\right)+\ddot{u}_{j}\left(t_{i+1}\right)\right)\right] \Delta t^{2}
\end{array}\right\} .
\end{aligned}
$$

Summing up over all time steps for the total gives

$$
E_{O}(t)=\sum_{1}^{n=t / \Delta t} \Delta E_{O}(n)
$$

Using MATLAB [29], we can develop the energy equations for $\Delta E_{D}$ and $\Delta E_{F}$,

$$
\begin{aligned}
\Delta E_{D}(n)+\Delta E_{F}(n) & =c_{1}\left\{\dot{u}_{1}^{2}\left(t_{i}\right) \Delta t+\dot{u}_{1}\left(t_{i}\right)\left(\ddot{u}_{1}\left(t_{i}\right)+\ddot{u}_{1}\left(t_{i+1}\right)\right) \frac{\Delta t^{2}}{2}+\frac{\left(\ddot{u}_{1}\left(t_{i}\right)+\ddot{u}_{1}\left(t_{i+1}\right)\right)^{2}}{12} \Delta t^{3}\right\}+\left(c_{1}+c_{2}\right) \\
& \left\{\dot{u}_{2}^{2}\left(t_{i}\right) \Delta t+\dot{u}_{2}\left(t_{i}\right)\left(\ddot{u}_{2}\left(t_{i}\right)+\ddot{u}_{2}\left(t_{i+1}\right)\right) \frac{\Delta t^{2}}{2}+\frac{\left(\ddot{u}_{2}\left(t_{i}\right)+\ddot{u}_{2}\left(t_{i+1}\right)\right)^{2}}{12} \Delta t^{3}\right\}-2 c_{1} \dot{u}_{1}\left(t_{i}\right) \dot{u}_{2}\left(t_{i}\right) \Delta t \\
& -c_{1} \dot{u}_{1}\left(t_{i}\right) \frac{\left(\ddot{u}_{2}\left(t_{i}\right)+\ddot{u}_{2}\left(t_{i+1}\right)\right)^{2}}{2} \Delta t^{2}-c_{1} \dot{u}_{2}\left(t_{i}\right) \frac{\left(\ddot{u}_{1}\left(t_{i}\right)+\ddot{u}_{1}\left(t_{i+1}\right)\right)^{2}}{2} \Delta t^{2}-c_{1} \frac{\left(\ddot{u}_{1}\left(t_{i}\right)+\ddot{u}_{1}\left(t_{i+1}\right)\right)\left(\ddot{u}_{2}\left(t_{i}\right)+\ddot{u}_{2}\left(t_{i+1}\right)\right)}{6} \Delta t^{3},
\end{aligned}
$$

and the mass-damping and friction hysteretic energy

$$
E_{D}(t)+E_{F}(t)=\sum_{1}^{t / \Delta t}\left[\Delta E_{D}(n)+\Delta E_{F}(n)\right] .
$$

In the following sections, measured earthquake wave signals are used as case studies in the model developed above for numerical solutions of the response isolated bridges with FPBs.

\section{Numerical Solutions}

4.1. Multihazard Source Excitations. El Centro [30] was the seismic wave signals recorded in 1940 and has been widely used in seismic response analyses. Taft [30] was another wave signal recorded in 1952. The traces of the wave signals are shown in Figures 5 and 6, respectively, and their characteristics are given in Table 1 . As case studies, the peak accelerations of the two waves were adjusted to $0.3 \mathrm{~g}$ and $0.4 \mathrm{~g}$, following the US bridge design code AASHTO LRFD [31] for the seismic zone four, representing two cases of the seismic fortification intensity, respectively.

4.2. Time Step. The published data on the time step of El Centro and Taft waves available by recording were $0.02 \mathrm{~s}$. And the energy responses of isolated bridges with FPB in different time steps (e.g., $0.02 \mathrm{~s}, 0.01 \mathrm{~s}, 0.005 \mathrm{~s}$, and $0.0025 \mathrm{~s}$ ) were obtained; the detailed data are shown in Figure 7 and Tables 2 and 3, respectively. Figure 7 and Table 2 show the influence of time step on the time history and amplitudes of 


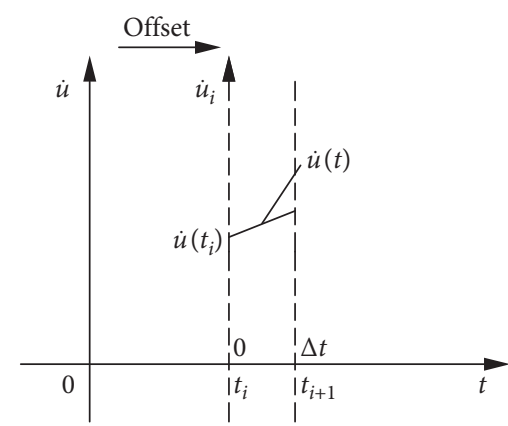

Figure 4: Velocity variation in time step.

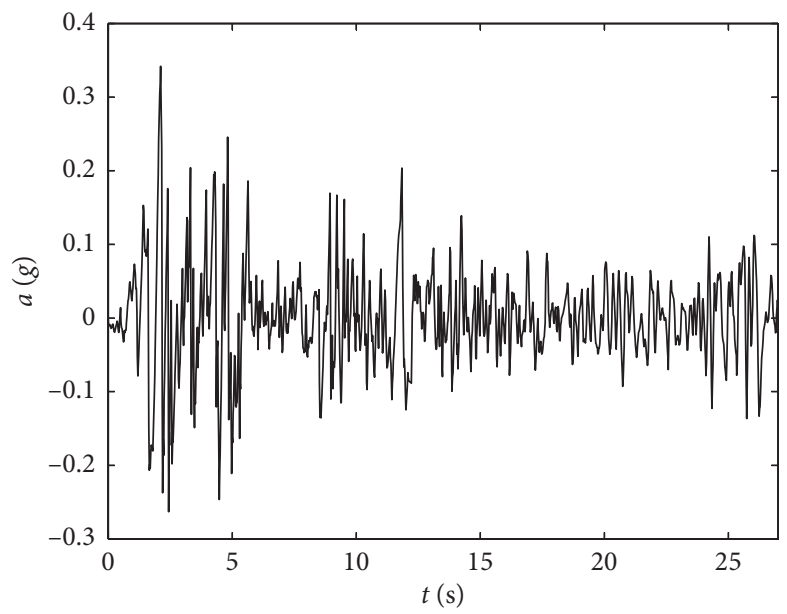

Figure 5: El Centro seismic wave.

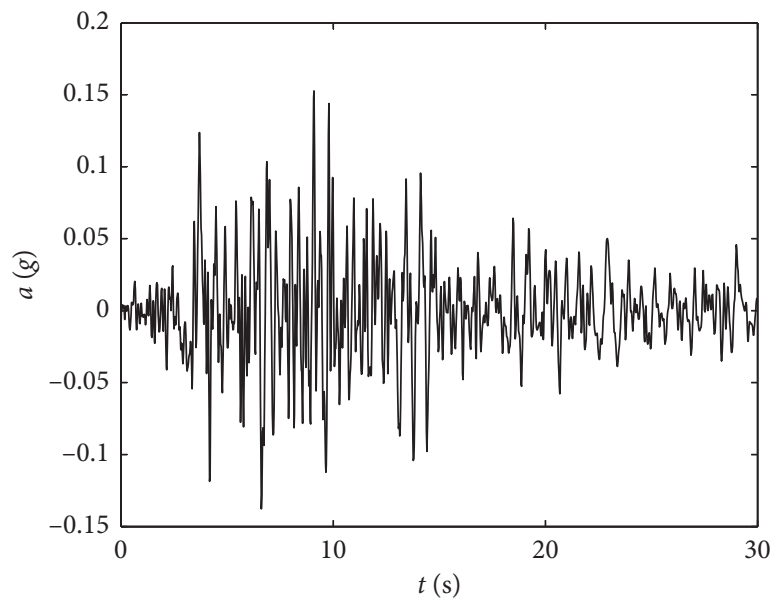

Figure 6: Taft seismic wave.

TABLE 1: Characteristics of seismic waves.

\begin{tabular}{llcc}
\hline Wave & $\begin{array}{c}\text { Peak acceleration }(g) \\
\text { corresponding to the } \\
\text { acceleration } \\
\text { coefficient }\end{array}$ & Duration (s) & Dominant period of the ground motion (s) \\
\hline El Centro & 0.4 & 27 & 0.54 \\
Taft & 0.3 & 30 & 0.36 \\
\hline
\end{tabular}




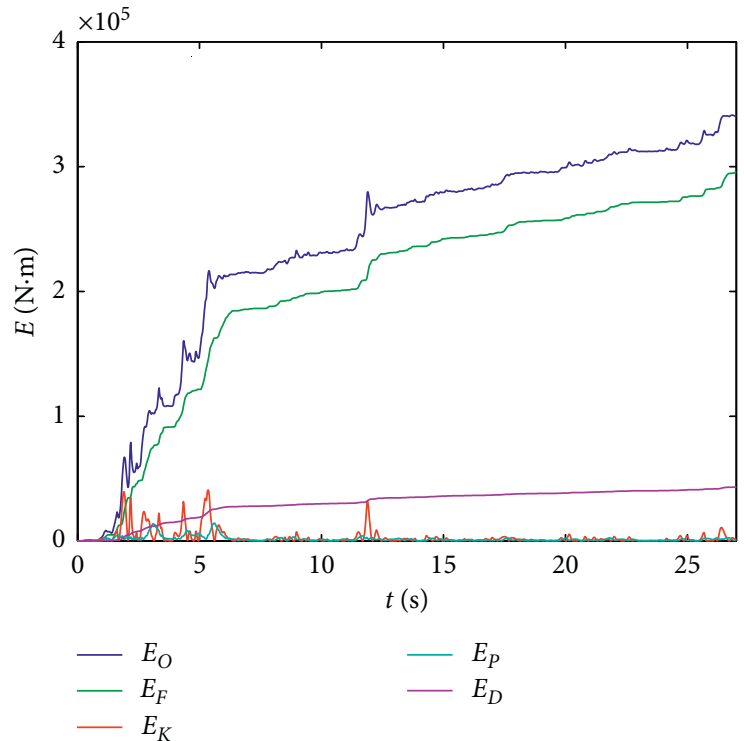

(a)

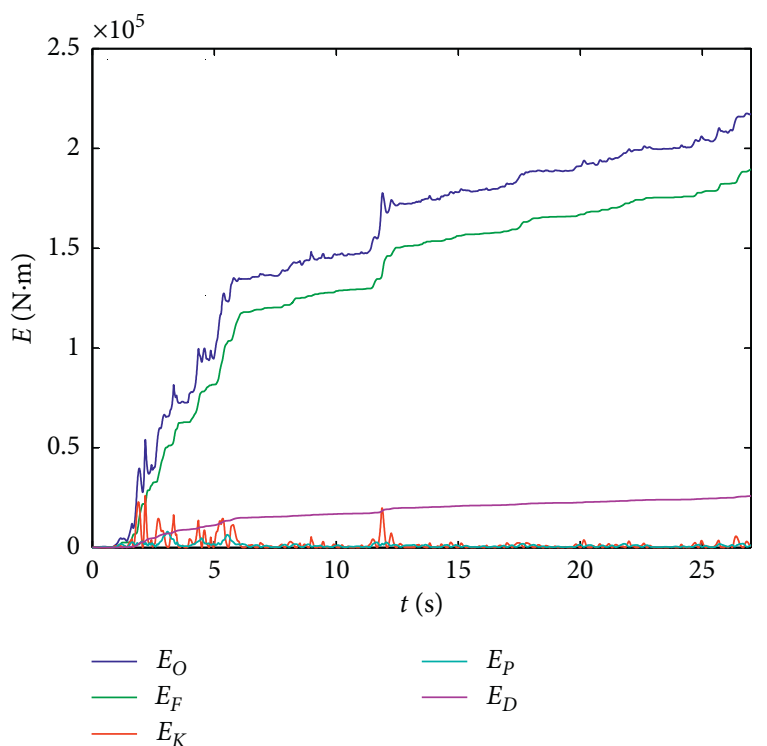

(c)

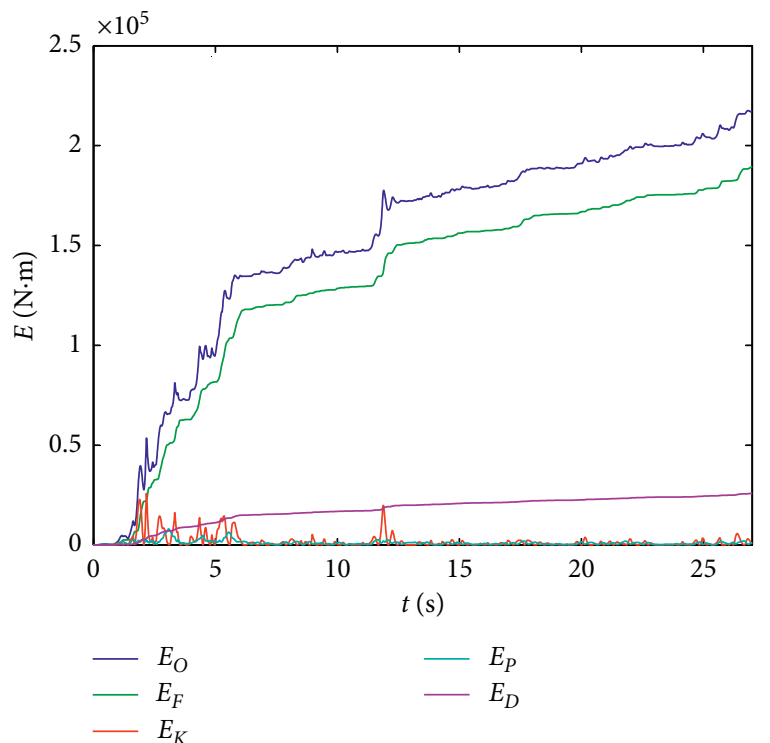

(b)
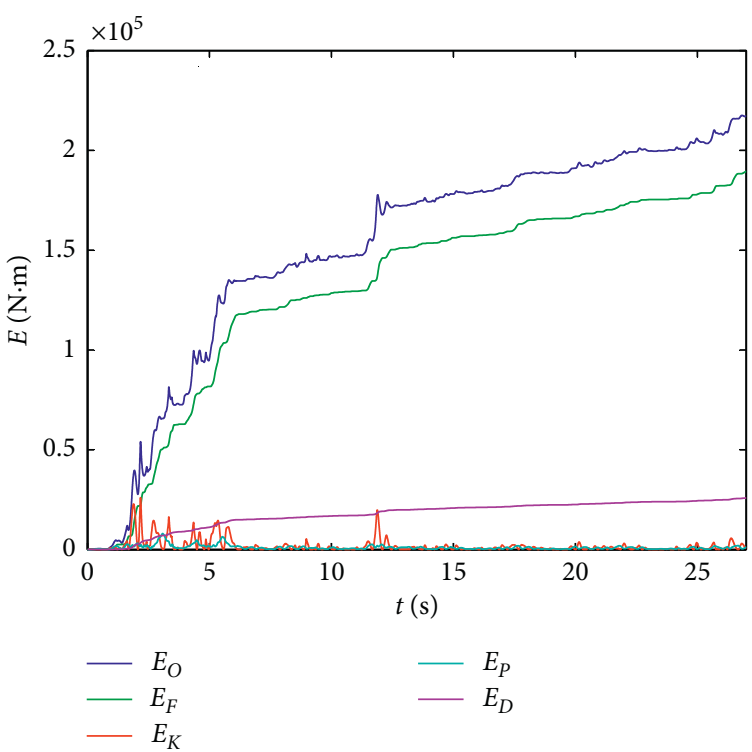

(d)

Figure 7: Comparison of time history of the energy response in different time steps, $T_{g}=2.84 \mathrm{~s}, \mu=0.05$; El Centro seismic wave; peak acceleration is $0.4 \mathrm{~g}$. (a) $\Delta t=0.02 \mathrm{~s}$, (b) $\Delta t=0.01 \mathrm{~s}$, (c) $\Delta t=0.005 \mathrm{~s}$, and (d) $\Delta t=0.0025 \mathrm{~s}$.

TABle 2: Amplitudes of energy response: the El Centro seismic wave.

\begin{tabular}{lccccc}
\hline $\begin{array}{l}\text { Step time } \\
(\mathrm{s})\end{array}$ & $\begin{array}{c}E_{O} \\
(\mathrm{~N} \cdot \mathrm{m})\end{array}$ & $\begin{array}{c}E_{F} \\
(\mathrm{~N} \cdot \mathrm{m})\end{array}$ & $\begin{array}{c}E_{K} \\
(\mathrm{~N} \cdot \mathrm{m})\end{array}$ & $\begin{array}{c}E_{P} \\
(\mathrm{~N} \cdot \mathrm{m})\end{array}$ & $\begin{array}{c}E_{D} \\
(\mathrm{~N} \cdot \mathrm{m})\end{array}$ \\
\hline 0.02 & 341360 & 295510 & 40865 & 14331 & 43265 \\
0.01 & 217500 & 189450 & 25740 & 8029 & 25831 \\
0.005 & 217510 & 189460 & 25994 & 8033 & 25829 \\
0.0025 & 217490 & 189450 & 26017 & 8033 & 25826 \\
\hline
\end{tabular}

the energy response under the El Centro wave with a peak acceleration of $0.4 \mathrm{~g}$, respectively. The appropriate time step should be selected according to the seismic wave to ensure
TABLE 3: Amplitudes of energy response: the TAFT seismic wave.

\begin{tabular}{lccccc}
\hline $\begin{array}{l}\text { Step time } \\
(\mathrm{s})\end{array}$ & $\begin{array}{c}E_{O} \\
(\mathrm{~N} \cdot \mathrm{m})\end{array}$ & $\begin{array}{c}E_{F} \\
(\mathrm{~N} \cdot \mathrm{m})\end{array}$ & $\begin{array}{c}E_{K} \\
(\mathrm{~N} \cdot \mathrm{m})\end{array}$ & $\begin{array}{c}E_{P} \\
(\mathrm{~N} \cdot \mathrm{m})\end{array}$ & $\begin{array}{c}E_{D} \\
(\mathrm{~N} \cdot \mathrm{m})\end{array}$ \\
\hline 0.02 & 457200 & 409142 & 66571 & 22060 & 46828 \\
0.01 & 457225 & 409223 & 66485 & 21966 & 46772 \\
0.005 & 457192 & 409356 & 66495 & 21975 & 46805 \\
0.0025 & 457180 & 409428 & 66485 & 21968 & 46800 \\
\hline
\end{tabular}

the convergence and efficiency of a computational algorithm. It can be seen that the results are basically consistent when the time step is less than $0.01 \mathrm{~s}$, so the time step should 
be selected as $0.01 \mathrm{~s}$ for the loading case of El Centro. And the time step should be selected as $0.02 \mathrm{~s}$ for the loading case of TAFT according to Table 3.

4.3. Calculated Time History of the Energy Response. To study the energy variation over time, the time history of energy response of an FPB isolated bridge was solved using the model discussed in Section 3. The structural parameters of the bridge are given in Appendix B. In the calculation, the isolation period of the FPB was taken as $2.84 \mathrm{~s}$ and the friction coefficient as 0.05 . Table 4 shows the kinetic parameters of the bridge system, with $k_{1}$ and $c_{1}$ being calculated by equations (2) and (5), and the peak accelerations of the seismic wave was set to $0.4 \mathrm{~g}$. As the horizontal displacement $D$ is related to the seismic wave, kinetic parameters are different in the cases of El Centro and Taft. Figure 8 illustrates the time history of the energy response.

In Figure 9, $E_{O}$ is the seismic input energy obtained by the right hand side of equation (6). $E_{O}^{\prime}$ is the summation of the left hand terms of equation (7). The two results are virtually identical through the duration of seismic waves. It can be seen that the seismic input energy $E_{O}$, the friction hysteretic energy $E_{F}$, and the mass-damping energy $E_{D}$ all increase with the duration of seismic waves. The numerical results indicate a highly effective damping effect of FPBs with around $90 \%$ of total input energy dissipated through friction $\left(E_{F}\right.$ to $\left.E_{O}\right)$.

\section{Finite Element Modelling}

5.1. Results of the SAP2000 Model. A finite element model was built for a four-span continuous bridge section using SAP2000 [26], a commercially available finite element code for the general structural analysis. The model is shown in Figure 9, including five piers and ten FPBs, with two FPBs on each pier. Mid-thick shell elements provided by the FE code were used for the beams and the piers. The frictional function of FPBs was modeled by the link-element available in the code. The link-element is a nonlinear element with the friction coefficient of FPB, the spherical radius of contact surfaces, and the vertical stiffness being the defined parameters. A mesh sensitivity study showed that a total of 725 elements and 855 nodes provide an appropriate model with good convergence.

5.2. Modal Analysis. Figure 10 shows the modal period and mode shape of formal six modes when the radius of the spherical pendulum bearing was set as $2 \mathrm{~m}$.

Mode 1 and mode 2 were the isolation modes of the bridge structure in transverse and longitudinal direction, respectively. The radius of the concave surface of FPB was constant in both directions, so the isolation periods of mode 1 and mode 2 were the same, and the isolation period was $2.95 \mathrm{~s}$. The isolation period calculated by theoretical calculation was $2.84 \mathrm{~s}$ according to equation (3). The results of numerical simulation and theoretical calculation were in good agreement.
TABle 4: Kinetic parameters when $T_{g}=2.84 \mathrm{~s}, \mu=0.05$, and the peak acceleration is $0.4 \mathrm{~g}$.

\begin{tabular}{lcccccccc}
\hline Parameters & $k_{1}$ & $k_{2}$ & $c_{1}$ & $c_{2}$ & $\varepsilon_{1}$ & $\varepsilon_{2}$ & $\omega_{1}$ & $\omega_{2}$ \\
\hline Unit & $\mathrm{N} /$ & $\mathrm{N} /$ & $\mathrm{N} \cdot \mathrm{s} /$ & $\mathrm{N} \cdot \mathrm{s} /$ & - & - & $\mathrm{Hz}$ & $\mathrm{Hz}$ \\
El Centro & $\mathrm{mm}$ & $\mathrm{mm}$ & $\mathrm{mm}$ & $\mathrm{mm}$ & - & & & \\
Taft & 6108 & 87000 & 1110 & 753 & 0.336 & 0.05 & 3.15 & 25.5 \\
\hline
\end{tabular}

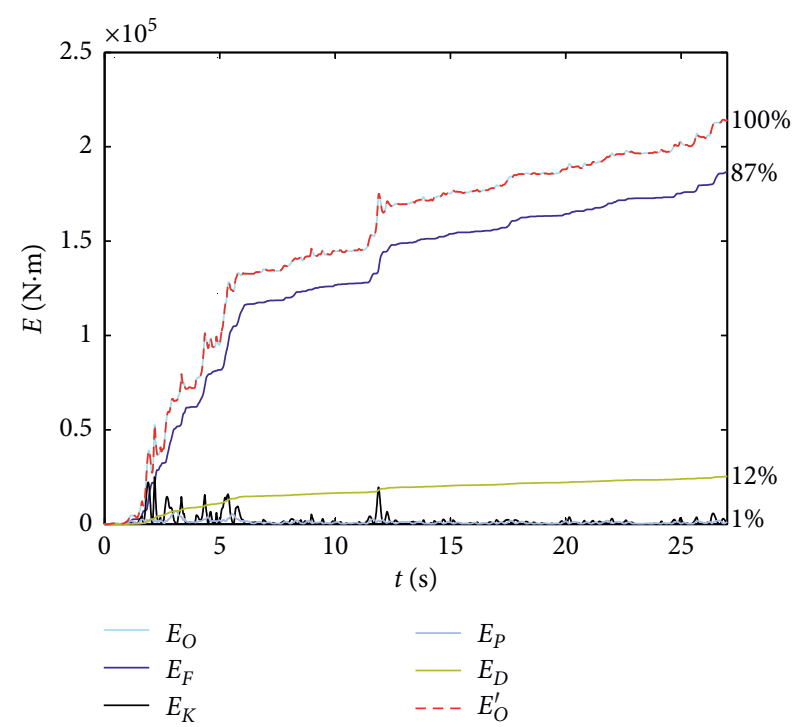

FIgURE 8: Time history of the energy response, $T_{g}=2.84 \mathrm{~s}, \mu=0.05$, and peak acceleration is $0.4 \mathrm{~g}$; El Centro wave.

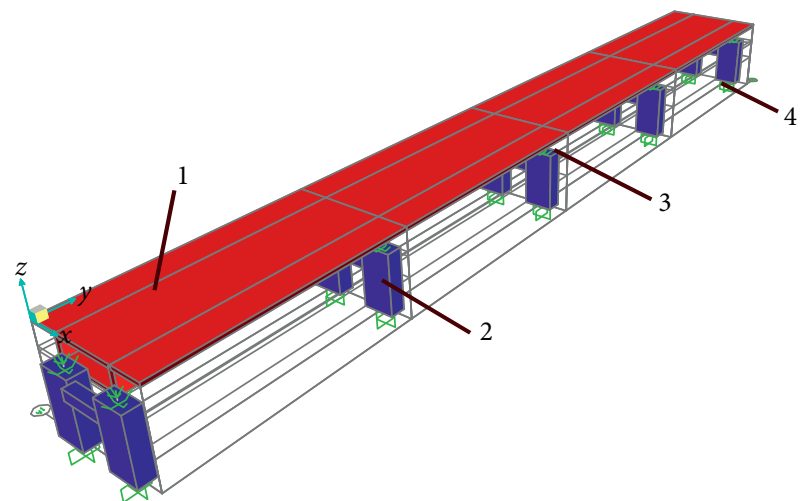

Figure 9: The finite element model of a four-span continuous beam bridge unit with FPBs. (1) Main bridge beam; (2) pier; (3) FPB; and (4) fixed boundary constraints to piers.

5.3. Influence of Structural Parameters on the Dynamic Responses of the Bridge. El Centro wave was used as the dynamic loading, with a peak acceleration of $0.4 \mathrm{~g}$. All structural and mechanical parameters used in the FE model were the same as in the theoretical analysis.

Figures 11(a) and 10(b) show the seismic input energy in terms of the frictional coefficient of FPB when the isolation period of the spherical pendulum bearing is set as $2.46 \mathrm{~s}$ and 


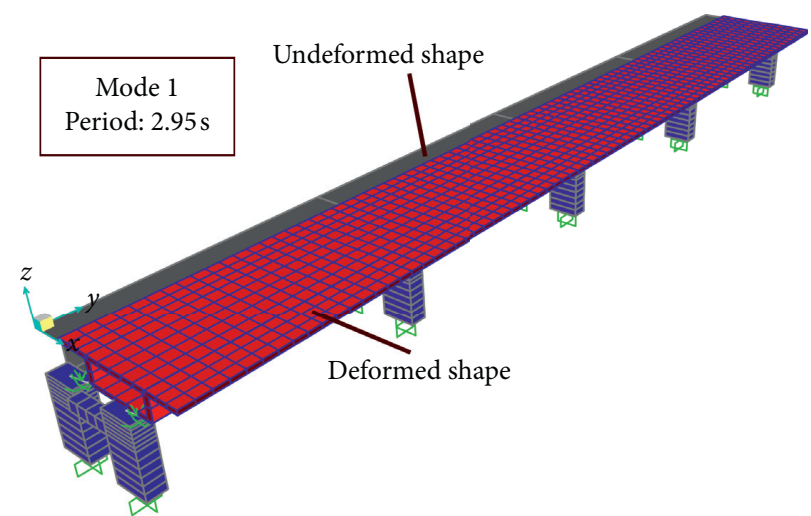

(a)

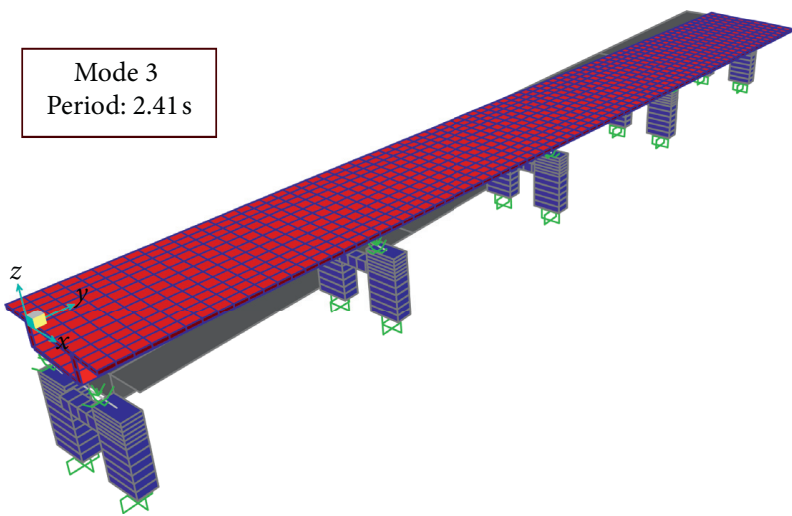

(c)

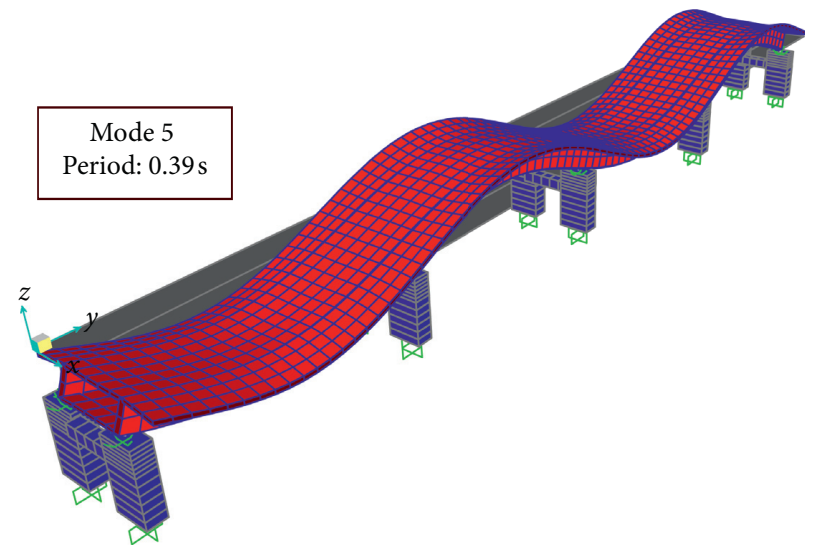

(e)

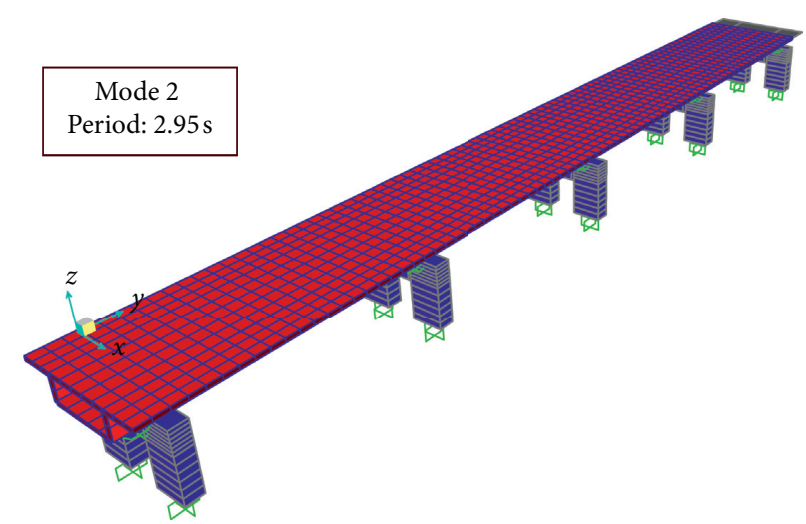

(b)

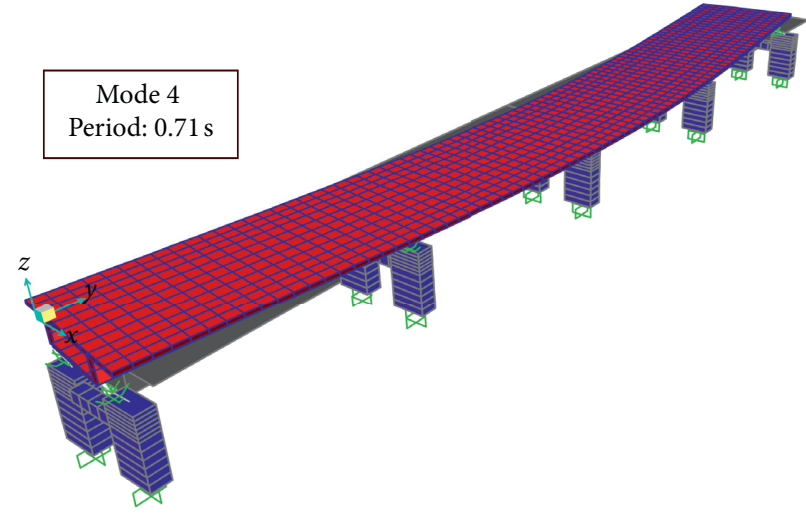

(d)

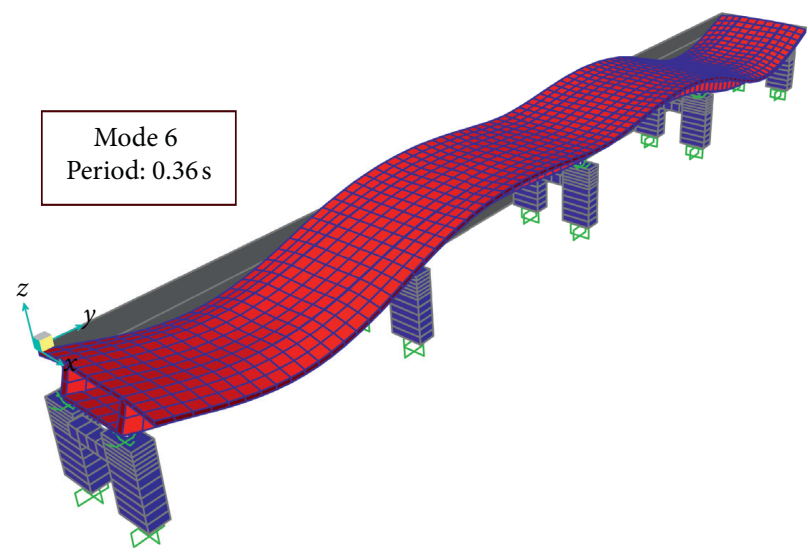

(f)

Figure 10: Modal periods and mode shapes when $R=2 \mathrm{~m}$.

$2.84 \mathrm{~s}$, respectively. The energy response of the theoretical and FEA results agrees well broadly. Figure 11 also illustrates that the input energy to the bridge increases approximately linearly with the friction coefficient under the small displacement assumption. And the isolation period appears to have only a moderate effect on the input energy.

In industrial practice, the pier stiffness $k_{2}$ is normally chosen in the range of $80-300 \mathrm{kN} / \mathrm{m}$ [32]. Taking the two range-end values (i.e., 80 and 300) as the minimum and maximum cases, Figure 12 illustrates the effect of $k_{2}$ on the response of the beam-pier system under the El Centro wave with a peak acceleration of $0.4 g$.
Figures 12(a) and 12(c) show that the dynamic responses of the main beam are virtually identical under the two range-end values, i.e., not affected by $k_{2}$. In contrast, the pier is more sensitive to $k_{2}$ (as shown in Figures 12(b) and 12(d)). It can be seen that both the displacement and the acceleration of the pier decrease when the pier becomes more rigid with a higher $k_{2}$.

5.4. Parameter Optimization of FPB. The energy dissipation of a FPB can be described by a ratio between its friction hysteretic energy and the seismic input energy, detonated as $\lambda$, 


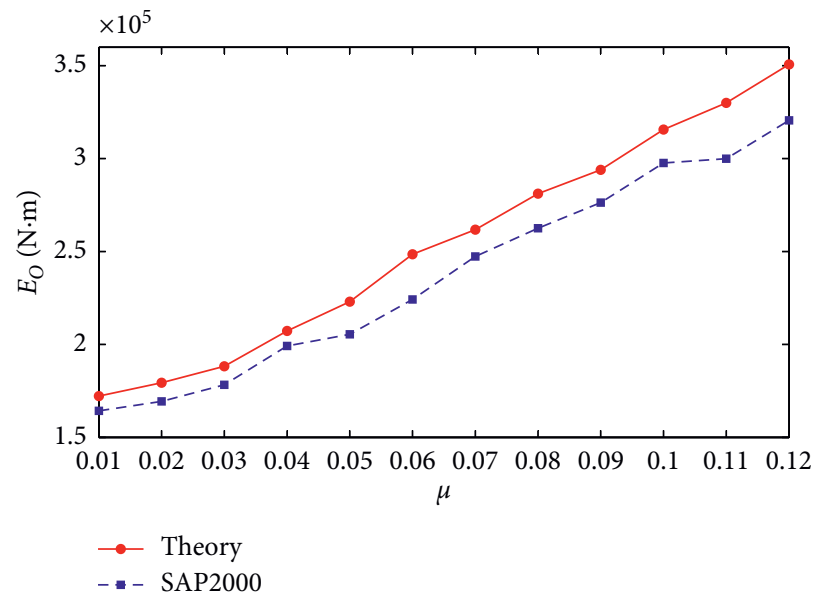

(a)

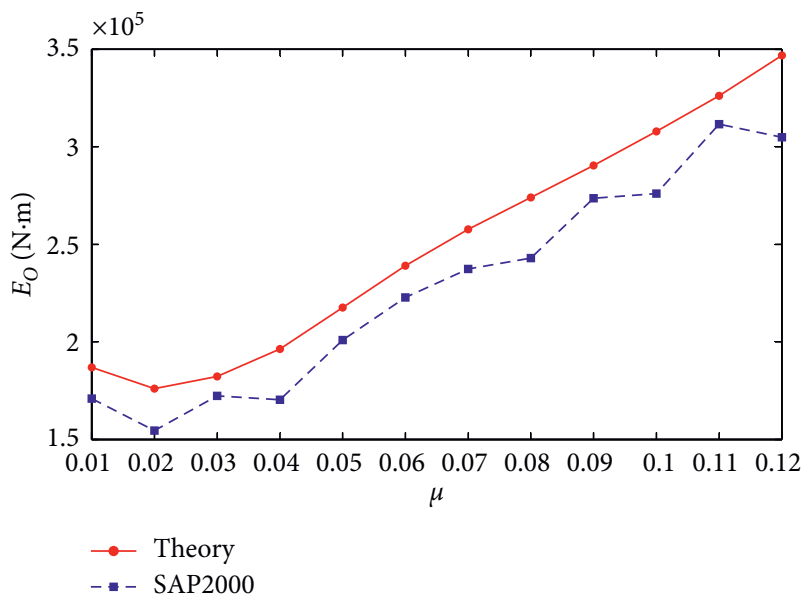

(b)

FIgURe 11: Comparison of seismic input energy between FE and analytical results. (a) $T_{g}=2.46 \mathrm{~s}$ and (b) $T_{g}=2.84 \mathrm{~s}$.

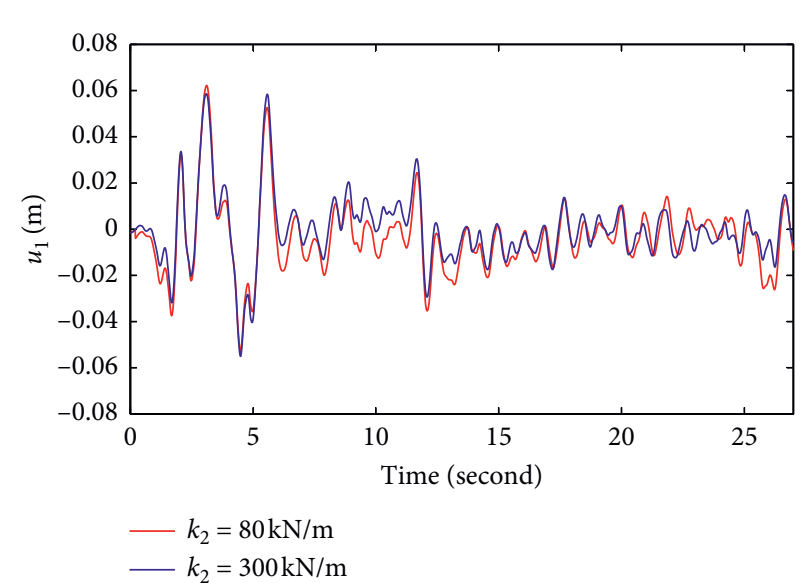

(a)

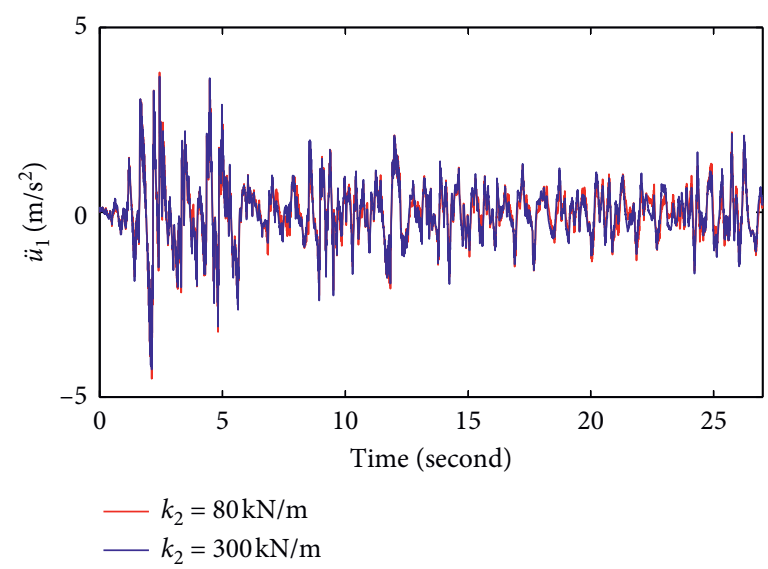

(c)

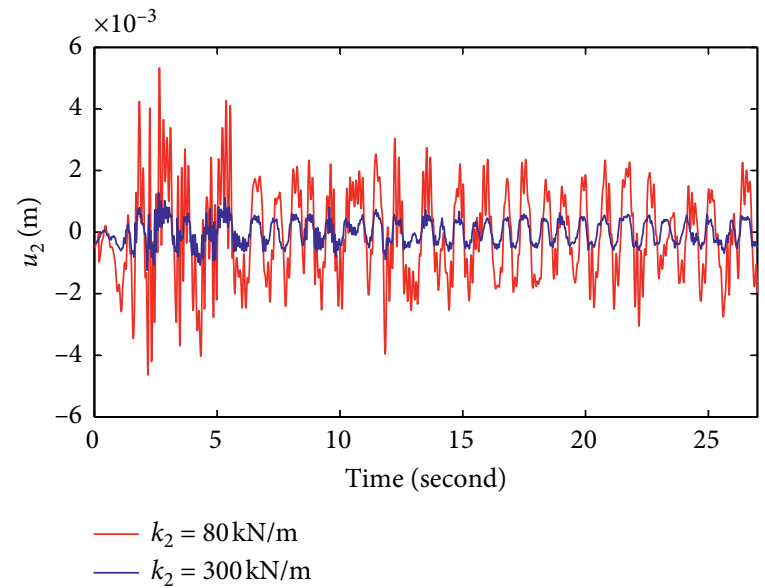

(b)

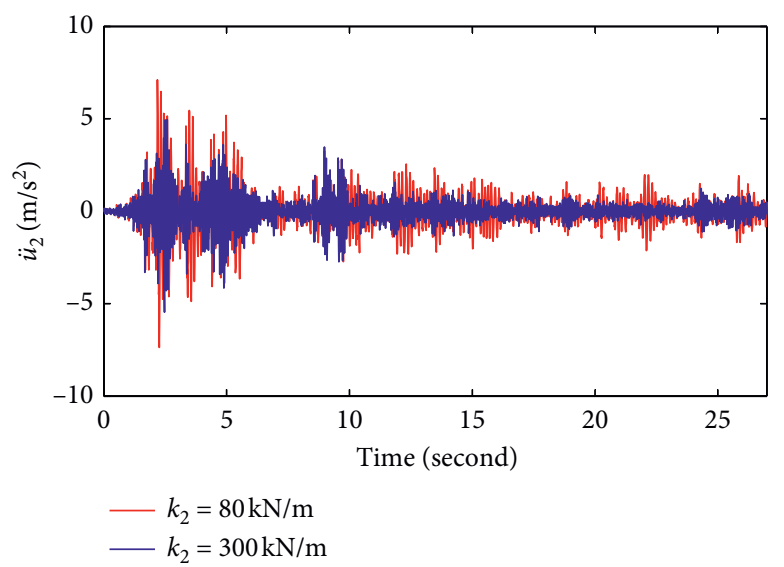

(d)

FiguRE 12: Comparison of the dynamic responses of the main beam and the pier for the minimum and maximum values of $k_{2} . T_{g}=2.84 \mathrm{~s}$, $\mu=0.05$. Minimum: $k_{2}=80 \mathrm{kN} / \mathrm{m}$. Maximum: $k_{2}=300 \mathrm{kN} / \mathrm{m}$. (a) Displacement of the main beam, (b) displacement of the pier, (c) acceleration of the main beam, and (d) acceleration of the pier. 


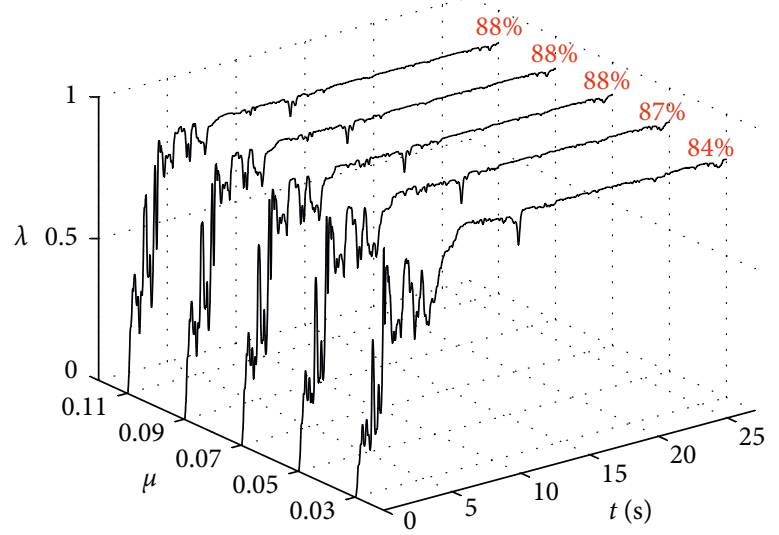

FIgURE 13: Time history of energy consuming ratio under the El Centro seismic wave, $T_{g}=2.84 \mathrm{~s}$ and peak acceleration is $0.4 \mathrm{~g}$.
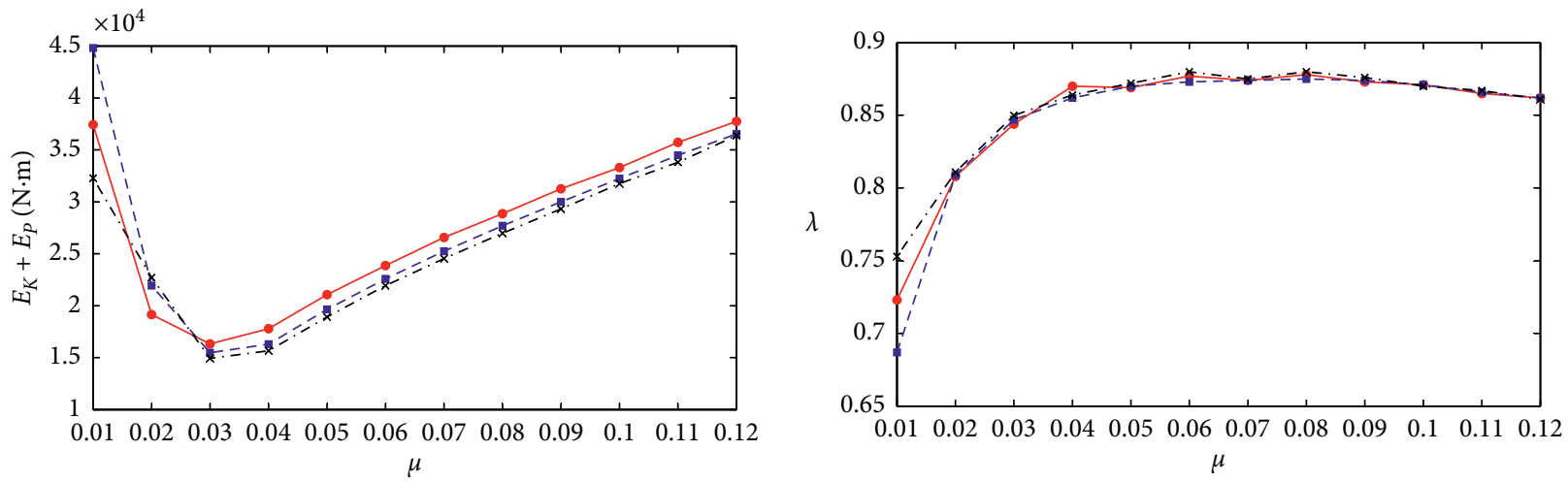

$\begin{aligned} \rightarrow & T_{g}=2.46 \mathrm{~s} \\ --T_{g} & =2.84 \mathrm{~s} \\ -*-T_{g} & =3.17 \mathrm{~s}\end{aligned}$

$$
\begin{aligned}
\because-T_{g} & =2.46 \mathrm{~s} \\
-- & T_{g}=2.84 \mathrm{~s} \\
-*-T_{g} & =3.17 \mathrm{~s}
\end{aligned}
$$

(a)
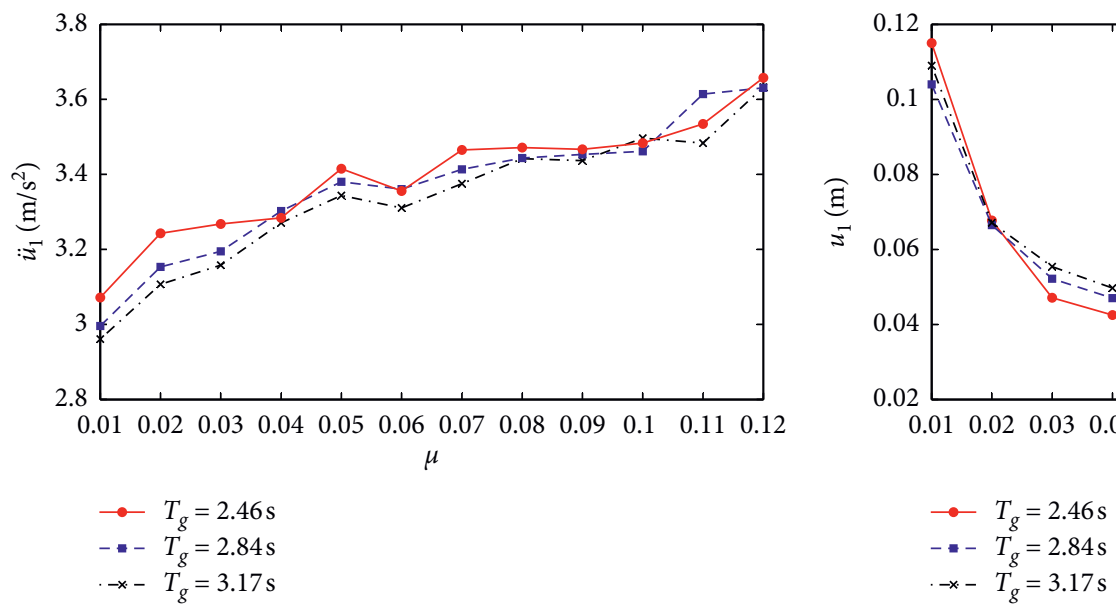

(b)

$$
\begin{aligned}
& \because T_{g}=2.46 \mathrm{~s} \\
& --T_{g}=2.84 \mathrm{~s} \\
& \because-T_{g}=3.17 \mathrm{~s}
\end{aligned}
$$

(c)

(d)

Figure 14: Seismic response amplitude (El Centro, peak acceleration 0.3g). (a) Structural response energy; (b) energy consuming ratio; (c) acceleration amplitude of the main beam; (d) displacement amplitude of the main beam. 

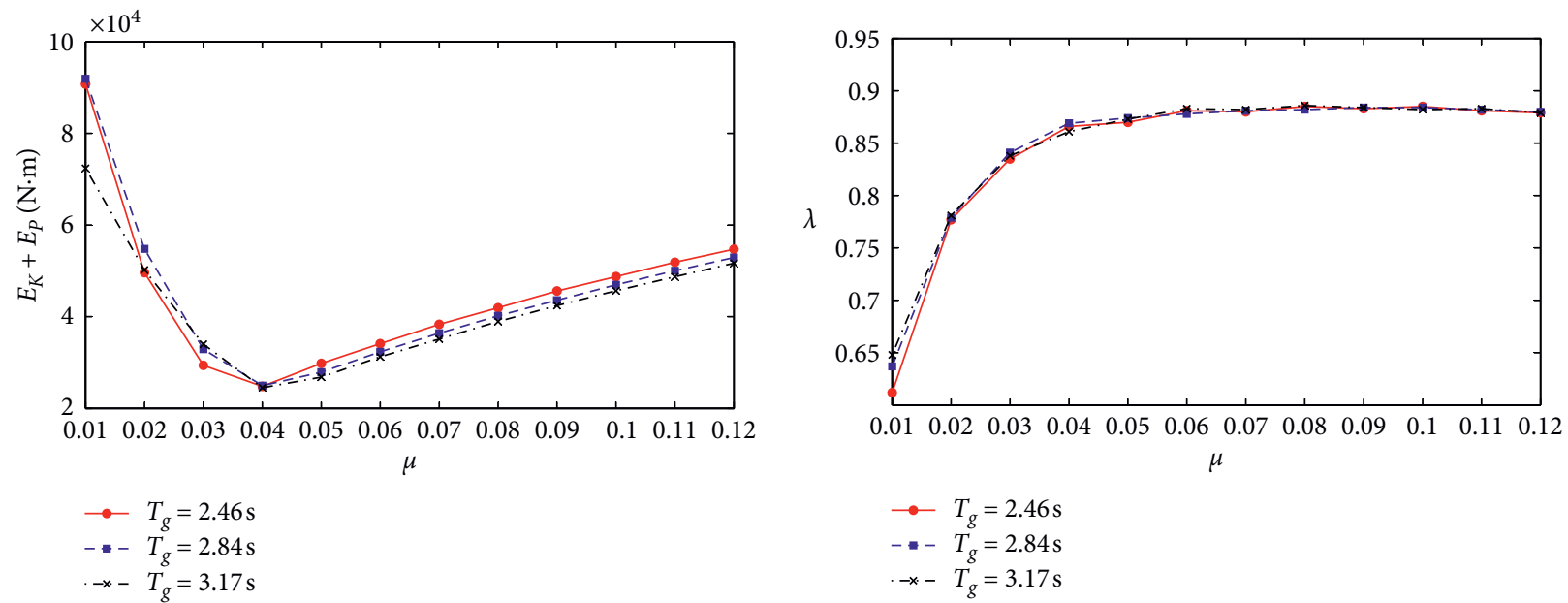

(a)

(b)
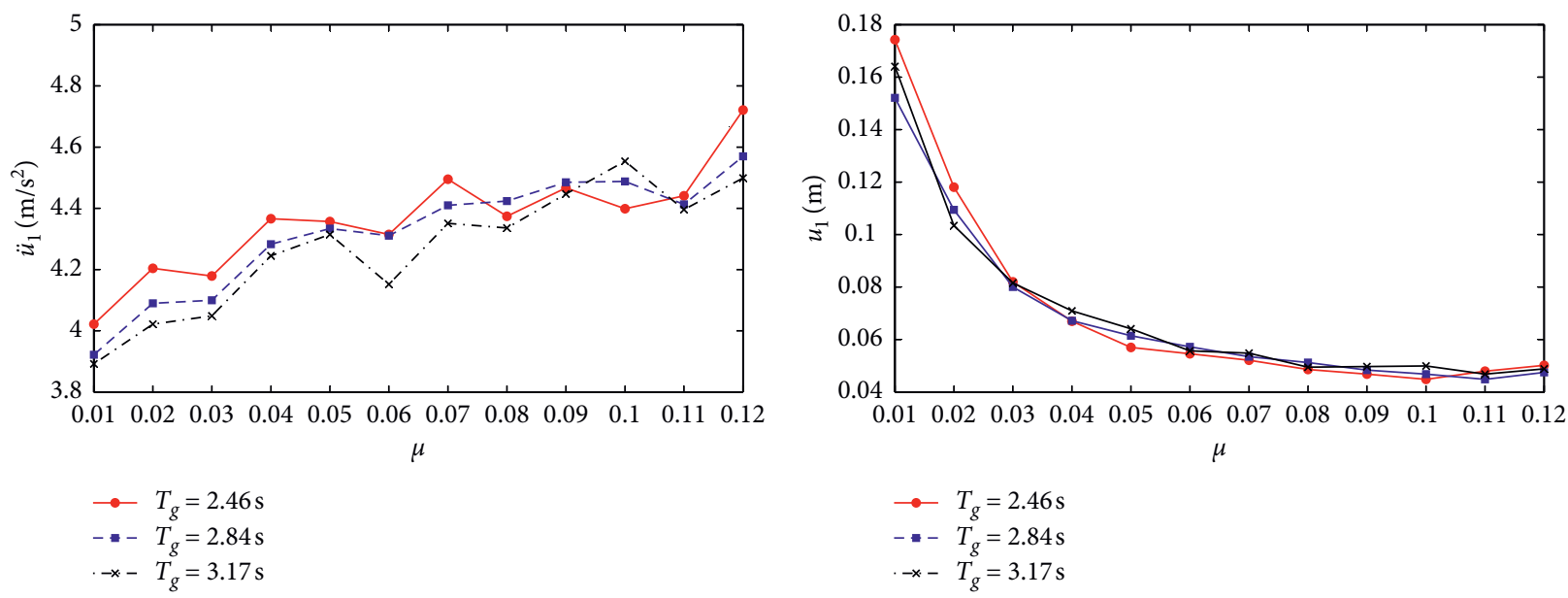

(c)

(d)

FIGURE 15: Seismic response amplitude (El Centro, peak acceleration 0.4g). (a) Structural response energy; (b) energy consuming ratio; (c) acceleration amplitude of the main beam; ( $\mathrm{d}$ displacement amplitude of the main beam.

$$
\lambda=\frac{E_{F}(t)}{E_{O}(t)}
$$

The control targets for design optimization are to minimize the structural response energy; to maximize the energy consuming ratio, thus a higher $\lambda$; and to minimize the acceleration and displacement of the main beam. For the two loading cases of EI Centro and Taft, design control parameters are discussed in more detail in the following sections based on theoretical calculations as discussed in Section 3.

5.4.1. El Centro Seismic Wave. Calculated time histories of $\lambda$ are shown in Figure 13 for different friction coefficients of FPB under El Centro wave of a peak acceleration of $0.4 \mathrm{~g}$. $\lambda$ first increases rapidly with time and reaches a plateau value close to the full capacity of energy dissipation of FPB. The percentage of dissipation increases slightly with an increasing frictional coefficient of FPBs.
Figures 14 and 15 show the influence of the peak acceleration on the kinetic and elastic strain energy, the energy dissipation ratio, the acceleration, and the displacement of the main beam versus the friction coefficient $\mu$. The influences of the isolation period of the FPB, $T_{g}$, are also included by three different values. It shows that in terms of the friction coefficient $\mu$, the structural response energy, the energy consuming ratio, and the main beam acceleration do not change monotonically. There is either a maximum or minimum, allowing optimal values to be chosen for design. For instance, for a minimum structural response energy, a maximum energy consuming ratio, and for a minimum acceleration and displacement of the main beam, an optimal value of $\mu$ and $R$ might be chosen as, respectively, $\mu=0.03$ 0.04 and $T_{g}=3.17 \mathrm{~s}$ for the peak seismic acceleration of $0.3 \mathrm{~g}$ and $\mu=0.04-0.05$ and $T_{g}=2.84 \mathrm{~s}-3.17 \mathrm{~s}$ for the peak acceleration of $0.4 \mathrm{~g}$.

5.4.2. Taft Seismic Wave. Similar to the loading of EI Centro, Figures 16-18 illustrate the influence on the structural 


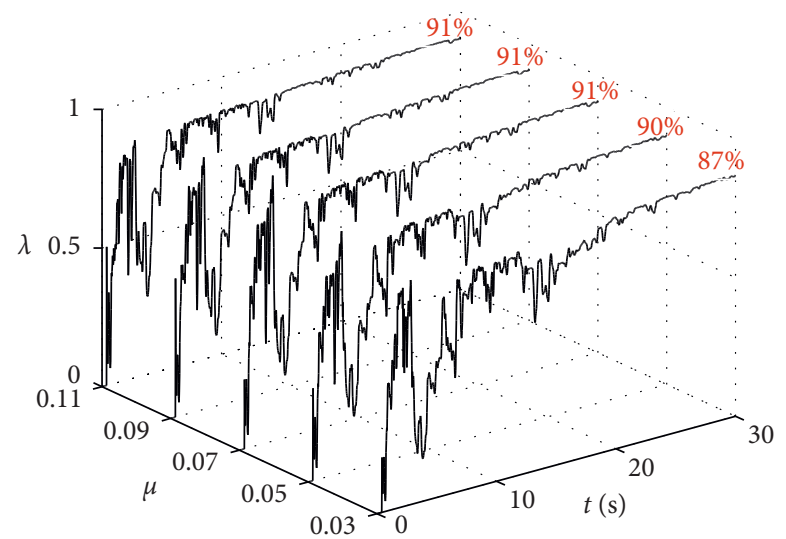

FIGURE 16: Time history response of energy consuming ratio when the Taft seismic wave $T_{g}=2.84 \mathrm{~s}$ and peak acceleration is $0.4 \mathrm{~g}$.
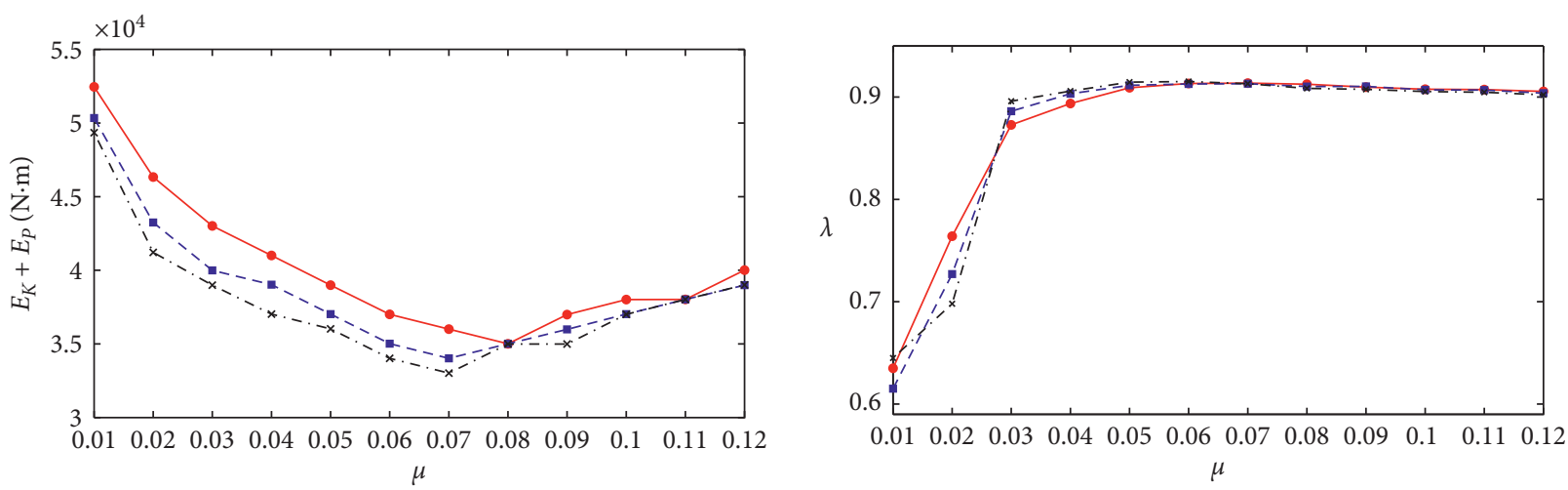

$\because T_{g}=2.46 \mathrm{~s}$

$\rightarrow T_{g}=2.46 \mathrm{~s}$

$-T_{g}=2.84 \mathrm{~s}$

$-T_{g}=2.84 \mathrm{~s}$

$-x-T_{g}=3.17 \mathrm{~s}$

$-x-T_{g}=3.17 \mathrm{~s}$

(a)

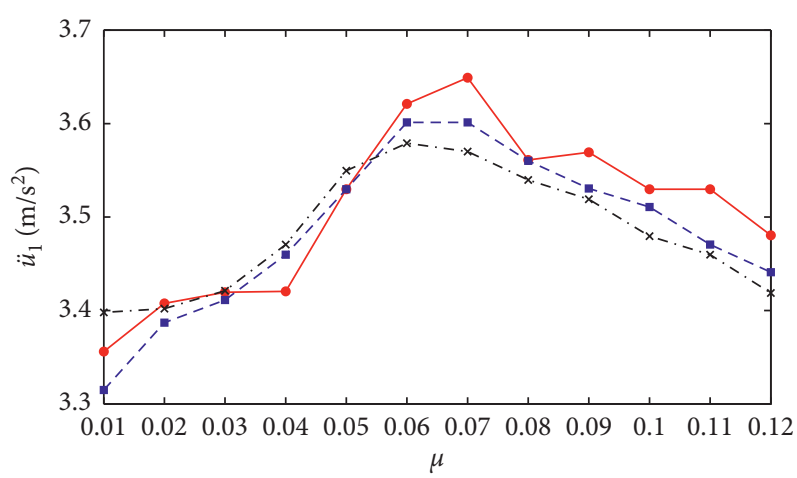

(b)

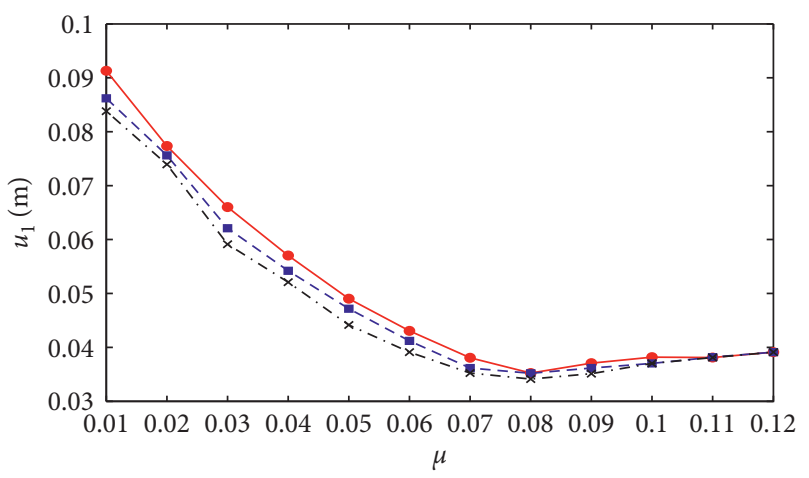

$$
\begin{aligned}
& \multimap T_{g}=2.46 \mathrm{~s} \\
& --T_{g}=2.84 \mathrm{~s} \\
& -\times-T_{g}=3.17 \mathrm{~s}
\end{aligned}
$$

$$
\begin{aligned}
\rightarrow-T_{g} & =2.46 \mathrm{~s} \\
--T_{g} & =2.84 \mathrm{~s} \\
-*-T_{g} & =3.17 \mathrm{~s}
\end{aligned}
$$

(c)

(d)

FIgURE 17: Seismic response amplitude (Taft, peak acceleration $0.3 \mathrm{~g}$ ). (a) Structural response energy; (b) energy consuming ratio; (c) acceleration amplitude of the main beam; (d) displacement amplitude of the main beam. 

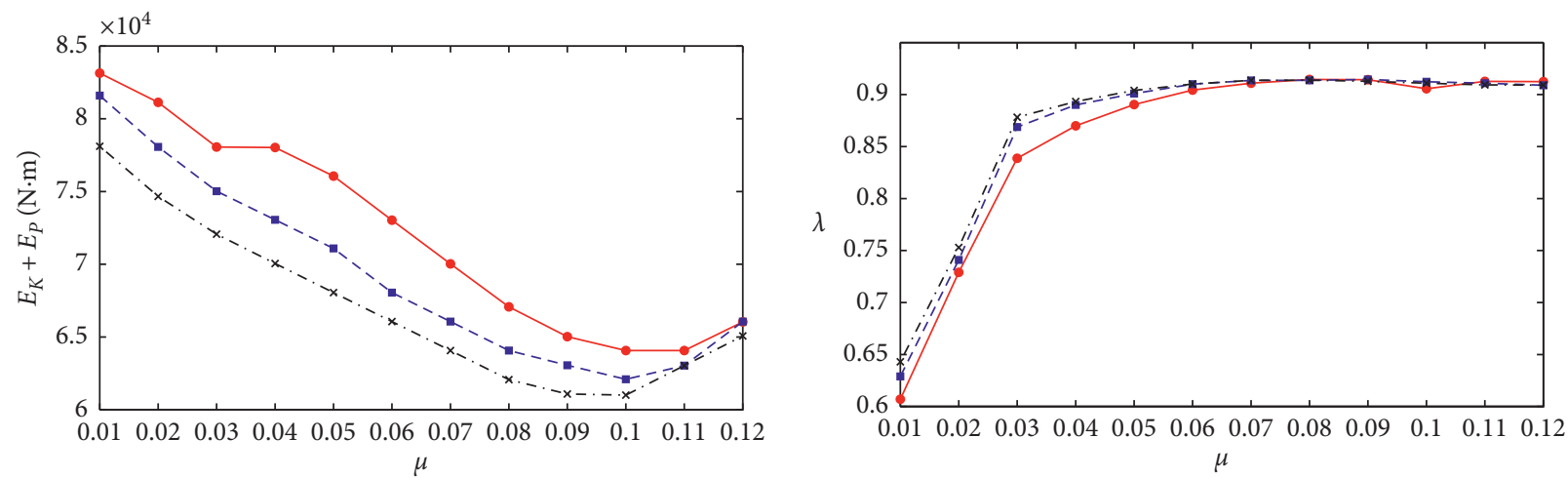

$$
\begin{aligned}
-T_{g} & =2.46 \mathrm{~s} \\
-T_{g} & =2.84 \mathrm{~s} \\
-x-T_{g} & =3.17 \mathrm{~s}
\end{aligned}
$$

$$
\begin{aligned}
& -T_{g}=2.46 \mathrm{~s} \\
& --T_{g}=2.84 \mathrm{~s} \\
& -*-T_{g}=3.17 \mathrm{~s}
\end{aligned}
$$

(a)

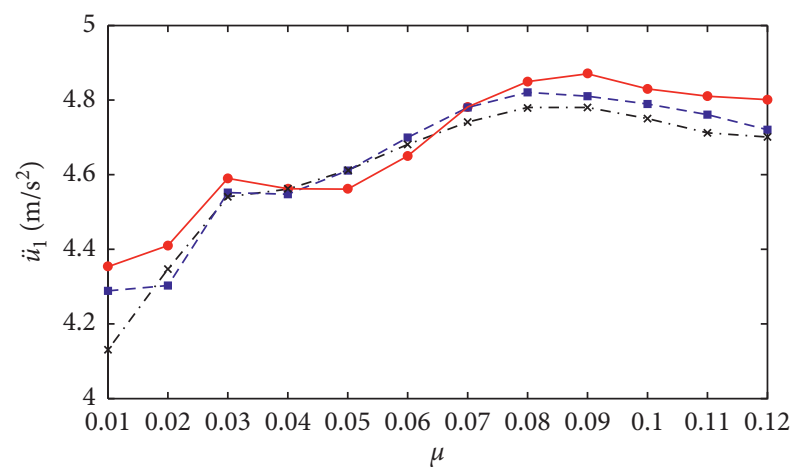

(b)

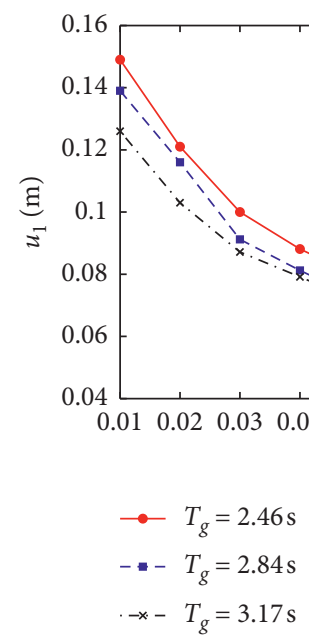

\begin{tabular}{|c|c|c|c|c|c|}
\hline \multirow{3}{*}{ Parameters } & \multicolumn{5}{|c|}{ Cases } \\
\hline & \multicolumn{2}{|c|}{ El Centro } & \multicolumn{2}{|c|}{ Taft } & \multirow{2}{*}{ Sichuan } \\
\hline & $0.3 g$ & $0.4 g$ & $0.3 g$ & $0.4 g$ & \\
\hline$\mu$ & $0.03-0.04$ & $0.04-0.05$ & $0.06-0.07$ & $0.09-0.1$ & $0.04-0.06$ \\
\hline$T_{g}$ & $3.17 \mathrm{~s}$ & $2.84 \mathrm{~s}-3.17 \mathrm{~s}$ & $3.17 \mathrm{~s}$ & $3.17 \mathrm{~s}$ & $3.17 \mathrm{~s}$ \\
\hline
\end{tabular}

(c)

(d)

FIGURE 18: Seismic response amplitude (Taft, peak acceleration 0.4g). (a) Structural response energy; (b) energy consuming ratio; (c) acceleration amplitude of the main beam; (d) displacement amplitude of the main beam.

TABle 5: The optimal parameters in different cases.

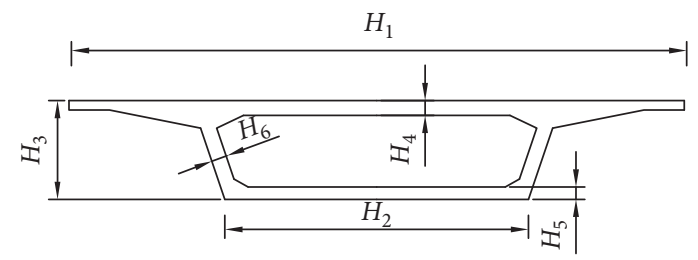

FIgURE 19: Cross section of span double line box beam. 


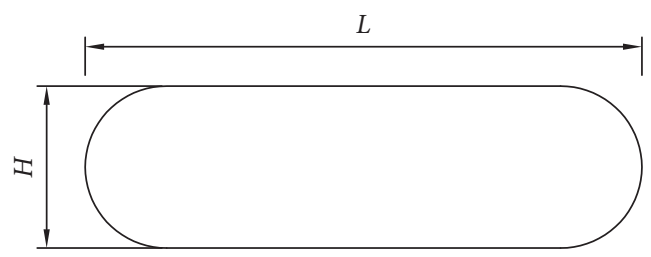

Figure 20: Cross section of round ended pier.

TABLE 6: Structural parameters of high-speed railway bridges.

\begin{tabular}{lcccccccccc}
\hline Parameters & $H_{1}$ & $H_{2}$ & $H_{3}$ & $H_{4}$ & $H_{5}$ & $H_{6}$ & $m_{1}$ & $H$ & $L$ \\
\hline Unit & $\mathrm{m}$ & $\mathrm{m}$ & $\mathrm{m}$ & $\mathrm{m}$ & $\mathrm{m}$ & $\mathrm{m}$ & $\mathrm{t}$ & $\mathrm{m}$ & $\mathrm{m}$ & $\mathrm{t}$ \\
Values & 12.4 & 6.12 & 2.00 & 0.30 & 0.25 & 0.45 & 510 & 1.5 & 6.3 & 142 \\
\hline
\end{tabular}

parameters under the Taft wave with peak accelerations of $0.3 g$ and $0.4 g$, respectively. Following the same analyses and discussions, we may draw the conclusion that the optimal design values of FPB unit might be chosen as $\mu=0.06-0.07$ and $T_{g}=3.17 \mathrm{~s}$ for the peak seismic acceleration $0.3 \mathrm{~g}$ and $\mu=0.09-0.1$ and $T_{g}=3.17 \mathrm{~s}$ for the peak acceleration is $0.4 g$.

A further case study is given here on the Sichuan Earthquake in 2008, which was measured at $8.0 \mathrm{Ms}$. Using the seismic data available, the optimal value of the friction coefficient and the spherical radius of FPB would be chosen as $\mu=0.03-0.05$ and $R=2.5 \mathrm{~m}$. Table 5 summaries the optimized parameters of the friction coefficient and the spherical radius in different cases.

\section{Conclusions}

Based on energy balance equations of continuous beam bridges with FPBs, analytical modelling and finite element simulations were carried out. Numerical results of the theoretical analysis agree well with those of the finite element modelling. It shows that in order to control the dynamic response of bridges under seismic loading, optimal design values can be chosen for the friction coefficient and the isolation period of FPB. The following conclusions can be drawn:

(1) The appropriate time step should be selected according to the seismic wave to ensure the convergence and efficiency of computational algorithm, and the time steps are selected as $0.01 \mathrm{~s}$ and $0.02 \mathrm{~s}$ for El Centro and TAFT waves, respectively.

(2) The seismic input energy to the bridge structure increases with the increase of the friction coefficient of $\mathrm{FPB}$, and the influence of the isolation period $(2.46 \mathrm{~s}-3.17 \mathrm{~s})$ on the seismic input energy to the bridge structure is less.
(3) Selection of the optimal values of the friction coefficient $\mu$ and the isolation period $T_{g}$ of FPB under different seismic loading can be based on the structural energy response and the dynamic response of the main beams. Recommended values of $\mu$ and $T_{g}$ were given for the benchmark wave data EI Centro and Taft. The structural energy response decreases with the increase of the isolation period of FPB.

(4) The longitudinal stiffness of piers should be increased to the upper end of the allowable range (such as those defined in design codes/standards) in order to decrease the peak displacement and acceleration of piers.

(5) The friction coefficient of FPB $\mu$ should be proportionally increased in line with the expected seismic fortification intensity.

(6) The energy dissipation ratio can reach up to $90 \%$ by introducing properly designed FPBs.

The proposed analytical modelling can be used for design optimization of FPBs for seismic loading isolation in bridges, through which, design guidelines and some recommended design values have been given. It should be noted that though the theoretical modelling and finite element simulations show good agreement, further comparison with experiment results, particularly fullscale site measurement is needed. This remains the scope for future work.

\section{Appendix}

\section{A. Derivation of Equivalent Damping Ratio}

FPB can be simplified equivalently as a viscous spring damper with one-degree of freedom. Energy dissipations of $\mathrm{FPB}$ in one cycle is given as 


$$
\begin{aligned}
\Delta E^{\prime} \int_{0}^{2 \pi / \omega} c_{1} \dot{x} \cdot \dot{x} \mathrm{~d} t & =\int_{0}^{2 \pi / \omega} c_{1}(D \omega \cos \omega t)^{2} \mathrm{~d} t=\int_{0}^{2 \pi / \omega} c_{1} D^{2} \omega^{2} \cos ^{2} \omega t \mathrm{~d} t \\
& =\int_{0}^{2 \pi / \omega} c_{1} D^{2} \omega^{2}\left(\frac{1+\cos 2 \omega t}{2}\right) \mathrm{d} t=\left.c_{1} D^{2} \omega^{2}\left(\frac{t}{2}+\frac{\sin 2 \omega t}{4 \omega}\right)\right|_{0} ^{2 \pi / \omega} \\
& =\pi c_{1} \omega D^{2}
\end{aligned}
$$

Following the classical vibration analysis, we have

$$
\begin{aligned}
c_{1} & =2 \varepsilon_{1} \sqrt{k_{1} m}, \\
\omega & =\sqrt{\frac{k_{1}}{m}} .
\end{aligned}
$$

Hence,

$$
\Delta E^{\prime}=\pi \cdot 2 \varepsilon_{1} \sqrt{k_{1} m} \cdot \sqrt{\frac{k_{1}}{m}} \cdot D^{2}=2 \pi \varepsilon_{1} k_{1} D^{2} .
$$

The hysteretic energy dissipation of FPB in one cycle is

$$
\Delta E=4 \mu W D \text {. }
$$

Let $\Delta E^{\prime}=\Delta E$, we have

$$
2 \pi \varepsilon_{1} k_{1} D^{2}=4 \mu W D .
$$

Substituting equation (2) into equation (A.5) leads to

$$
\varepsilon_{1}=\frac{2 \mu}{\pi(\mu+(D / R))} .
$$

\section{B. Details of an Isolated Bridge Unit Used in the Analysis}

The unit structure of an isolated bridge with FPB consists of a span of the main beam and a pier. The main beam is supported by FPB, with the FPB fixed on the top of the pier. Based on a high-speed railway bridge design, the main beam span considered here is $24 \mathrm{~m}$, and the height of the pier is $6 \mathrm{~m}$. Figures 19 and 20 show the cross sections of main beam and the pier. The mainly structural parameters of bridges are given in Table 6 , where $m_{1}$ and $m_{2}$ are the weight of the beam and the pier in metric ton.

\section{Data Availability}

All data relevant to the article will be made available upon request for research purpose.

\section{Conflicts of Interest}

The authors declare that they have no conflicts of interest.

\section{Acknowledgments}

This study was supported by the Doctoral Scientific Research Foundation of North China University of Water Resources and Electric Power and the Key Research Projects of Higher
Education Institutions in Henan (18A460004) and the International Exchanges Programme Scheme project by the Royal Society and National Natural Science Foundation of China (51811530311).

\section{References}

[1] T. L. Karavasillis, T. Blakeborough, and M. S. Williams, "Development of nonlinear analytical model and seismic analyses of a steel frame with self-centering devices and viscoelastic dampers," Computers \& Structures, vol. 89, no. 1112, pp. 1232-1240, 2011.

[2] R. S. Jangid, "Equivalent linear stochastic seismic response of isolated bridges," Journal of Sound and Vibration, vol. 309, no. 3-5, pp. 805-822, 2008.

[3] A. M. Avossa, D. D. Giacinto, P. Malangone, and F. Rizzo, "Seismic retrofit of a multispan prestressed concrete girder bridge with friction pendulum devices," Shock and Vibration, vol. 2018, Article ID 5679480, 22 pages, 2018.

[4] E. Tubaldi, A. Dall'Asta, and L. Dezi, "Seismic response analysis of continuous multispan bridges with partial isolation," Shock and Vibration, vol. 2015, Article ID 183756, 15 pages, 2015.

[5] H. Zhang, J. Li, and T. Peng, "Development and mechanical performance of a new kind of bridge seismic isolator for low seismic regions," Shock and Vibration, vol. 20, no. 4, pp. 725-735, 2013.

[6] M. Ismail, J. R. Casas, and J. Rodellar, "Near-fault isolation of cable-stayed bridges using an RNC isolator," Engineering Structures, vol. 56, pp. 327-342, 2013.

[7] M. Ismail and R. Casas, "Noval isolation device for protection of cable-stayed bridges against near-fault earthquakes," Journal of Bridge Engineering, vol. 19, no. 8, 2014.

[8] T. Y. Zhong, C. Y. Zhang, and F. L. Yang, "The parameter study of the seismically isolated bridge system by lead bearing based on energy analysis," in Proceedings of the International Symposium on Seismic Engineering, ASME, Baltimore, MD, USA, pp. 217-223, 2011.

[9] M. Dicleli, "Seismic design of lifeline bridge using hybrid seismic isolation," Journal of Bridge Engineering, vol. 7, no. 2, pp. 94-103, 2002.

[10] A. A. Taflanidis, "Optimal probabilistic design of seismic dampers for the protection of isolated bridges against nearfault seismic excitations," Engineering Structures, vol. 33, no. 12, pp. 3496-3508, 2011.

[11] S. Ates and M. C. Constantinou, "Example of application of response spectrum analysis for seismically isolated curved bridges including soil-foundation effects," Soil Dynamics and Earthquake Engineering, vol. 31, no. 4, pp. 648-661, 2011.

[12] R. S. Jangid, "Seismic response of isolated bridges," Journal of Bridge Engineering, vol. 9, no. 2, pp. 156-166, 2004.

[13] G. Mosqueda, A. S. Whittaker, and G. L. Fenves, "Characterization and modeling of friction pendulum bearings subjected to multiple components of excitation," 
Journal of Structural Engineering, vol. 130, no. 3, pp. 433-442, 2004.

[14] F. Khoshnoudian and A. Hemmati T, "Impact of structures with double concave friction pendulum bearings on adjacent structures," Proceedings of the Institution of Civil Engineers-Structures and Buildings, vol. 167, no. 1, pp. 41-53, 2014.

[15] Y.-S. Kim and C.-B. Yun, "Seismic response characteristics of bridges using double concave friction pendulum bearings with tri-linear behavior," Engineering Structures, vol. 29, no. 11, pp. 3082-3093, 2007.

[16] L. Yan, Q. Li, C. Han, and H. Jiang, "Shaking table tests of curved bridge considering bearing friction sliding isolation," Shock and Vibration, vol. 2016, Article ID 6245062, 14 pages, 2016.

[17] M. Dicleli and M. Y. Mansour, "Seismic retrofitting of highway bridges in Illinois using friction pendulum seismic isolation bearings and modeling procedures," Engineering Structures, vol. 25, no. 9, pp. 1139-1156, 2003.

[18] J. S. Hwang, K. C. Chang, and M. H. Tsai, "Composite damping ratio of seismically isolated regular bridges," Engineering Structures, vol. 19, no. 1, pp. 55-62, 1997.

[19] R. S. Jangid, "Stochastic response of bridges seismically isolated by friction pendulum system," Journal of Bridge Engineering, vol. 13, no. 4, pp. 319-330, 2008.

[20] R. S. Jangid, "Optimum friction pendulum system for nearfault motions," Engineering Structures, vol. 27, no. 3, pp. 349-359, 2005.

[21] S. Ates, D. Aydin Dumanoglu, and A. Bayraktar, "Stochastic response of seismically isolated highway bridges with friction pendulum systems to spatially varying earthquake ground motions," Engineering Structures, vol. 27, no. 13, pp. 1843$1858,2005$.

[22] M. Eröz and R. DesRoches, "Bridge seismic response as a function of the friction pendulum system (FPS) modeling assumptions," Engineering Structures, vol. 30, no. 11, pp. 3204-3212, 2008.

[23] M. Eröz and R. DesRoches, "The influence of design parameters on the response of bridges seismically isolated with the friction pendulum system (FPS)," Engineering Structures, vol. 56, no. 11, pp. 585-599, 2013.

[24] A. Saha, P. Saha, and S. K. Patro, "Polynomial friction pendulum isolators (PFPIs) for seismic performance control of benchmark highway bridge," Earthquake Engineering and Engineering Vibration, vol. 16, no. 4, pp. 827-840, 2017.

[25] A. Saha, P. Saha, and S. K. Patro, "Seismic protection of the benchmark highway bridge with passive hybrid control system," Earthquake Engineering, vol. 15, no. 3, pp. 227-241, 2018.

[26] Computers and Structures. Inc., SAP2000 Manuals, Computers and Structures. Inc., Walnut Creek, CA, USA, 2000.

[27] Optimization analysis of the equivalent linear model of friction pendulum bearing in preparation.

[28] M. Bruneau and N. Wang, "Some aspects of energy methods for the inelastic seismic response of ductile SDOF structures," Engineering Structures, vol. 18, no. 1, pp. 1-12, 1996.

[29] Apple Hill Drive, MATLAB Mathworks, Apple Hill Drive, Natick, MA, USA, 2000.

[30] Y. C. Kim, S. D. Xue, P. Zhuang, W. Zhao, and C. H. Li, "Seismic isolation analysis of FPS bearings in spatial lattice shell structures," Earthquake Engineering and Engineering Vibration, vol. 9, no. 1, pp. 93-102, 2010.

[31] AASHTO, AASHTO LRFD Bridge Design Specifications, AASHTO, Washington, DC, USA, 2005.

[32] J. Zheng, Chinese High-Speed Railway Bridges, High Education Press, China, Beijing, 2008, in Chinese. 